\title{
Psychophysical studies of binocular and spatial vision in humans with anisometropic and strabismic amblyopia
}

\author{
Ritwick Agrawal \\ West Virginia University
}

Follow this and additional works at: https://researchrepository.wvu.edu/etd

\section{Recommended Citation}

Agrawal, Ritwick, "Psychophysical studies of binocular and spatial vision in humans with anisometropic and strabismic amblyopia" (2004). Graduate Theses, Dissertations, and Problem Reports. 2002.

https://researchrepository.wvu.edu/etd/2002

This Thesis is protected by copyright and/or related rights. It has been brought to you by the The Research Repository @ WVU with permission from the rights-holder(s). You are free to use this Thesis in any way that is permitted by the copyright and related rights legislation that applies to your use. For other uses you must obtain permission from the rights-holder(s) directly, unless additional rights are indicated by a Creative Commons license in the record and/ or on the work itself. This Thesis has been accepted for inclusion in WVU Graduate Theses, Dissertations, and Problem Reports collection by an authorized administrator of The Research Repository @ WVU. For more information, please contact researchrepository@mail.wvu.edu. 


\title{
Psychophysical studies of binocular and spatial vision in humans with anisometropic and strabismic amblyopia
}

\author{
Ritwick Agrawal
}

\author{
Thesis submitted to the \\ School of Medicine \\ West Virginia University \\ in partial fulfillment to the requirements \\ for the degree of \\ Master of Science \\ in \\ Neuroscience
}

Janine D. Mendola, $\mathrm{PhD}$, advisor

J. Vernon Odom, PhD

Aina Puce, $\mathrm{PhD}$

Department of Neurobiology and Anatomy

Morgantown, West Virginia

2004 


\begin{abstract}
Psychophysical studies of binocular and spatial vision in humans with anisometropic and strabismic amblyopia
\end{abstract}

\title{
Ritwick Agrawal
}

Amblyopia is a common developmental visual disorder. Previous studies of amblyopia have delineated spatial and binocular deficits. However debate exists about how the strabismic and anisometropic subtypes may differ. The central hypothesis is that the two subtypes differ with regard to binocular integration functions. Strabismic subjects may show severe impairments of binocular integration due to a history inter-ocular suppression, which predicts the pattern of monocular deficits. Seven anisometropic, six strabismic and seven control subjects were tested psychophysically with four monocular tests and three binocular tests. Results indicated that the degree of loss of Vernier acuity was larger than that predicted from grating acuity in strabismics but was predictable in anisometropics. Amblyopes demonstrated significant loss in binocularity, and loss in binocularity predicted loss in Vernier acuity. The results help to explain the mechanisms of vision loss and suggest that extrastriate visual cortex may be an important site of abnormality in amblyopia. 
Dedicated to

my father

who showed me the path of success,

to my mother

who nurtured me with her immense love and inspiration, and to my teachers

who shaped me as a better person at each step of my life. 


\section{Acknowledgements}

Research is the advancement which arrives by the combined efforts of a number of people, and not by a single entity. I felt this phrase literally while working on my research, and I am grateful for help I received from many people. I would like to thank my advisor, Dr. Janine Mendola for guiding me throughout my project, for trusting my capabilities, and teaching me not only the science but the "art" of research as well; Dr. J. V. Odom for explaining me some the most difficult concept in psychophysics, and encouraging me for my work; Dr A. Puce for the her valuable suggestions at various points of the project.

I owe special thanks to Ruth Walsh, for providing me support with different aspects of experiments like scheduling the subjects, making the instructions and so many similar seemingly trivial but immensely important works; to Amol Bahekar for being the best friend and helping me out for practically anytime I needed his help; to Ian Conner for helping me with all the aspects of my research, a person whom I can count anytime I was in problem with technical or conceptual part of my research; and to James Trimmier for all the complicated software related helps arising from time to time. Finally, I want to extend my thanks to all the friends who had volunteered at several parts of research as the subjects. 
IINTRODUCTION AND BACKGROUND .............................................................................................. 1

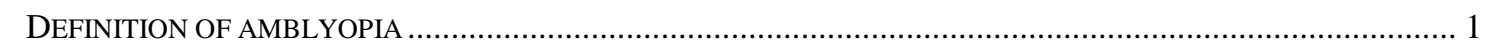

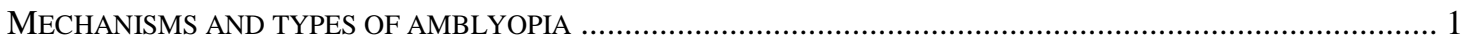

COMMON TECHNIQUES USED TO STUDY THE VISUAL PROPERTIES IN AMBLYOPIA .............................. 4

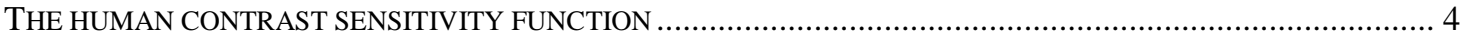

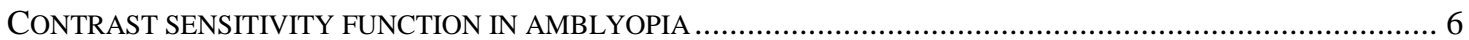

DIFFERENCES IN THE VISUAL ABNORMALITIES OF THE TWO TYPES OF AMBLYOPIA $\ldots \ldots \ldots \ldots \ldots \ldots \ldots \ldots \ldots \ldots$

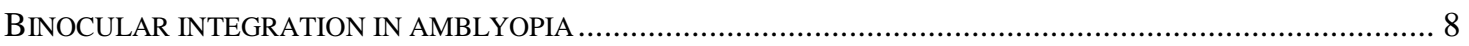

METHODS............................................................................................................................................ 10

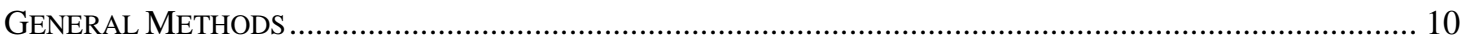

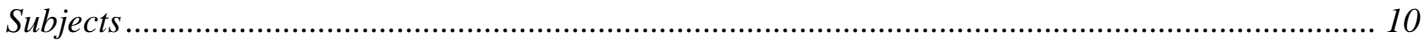

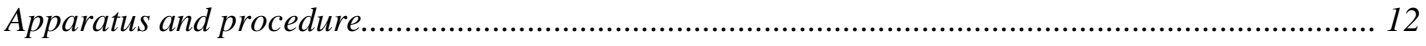

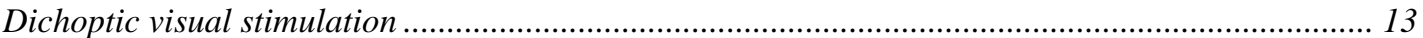

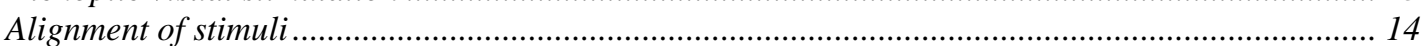

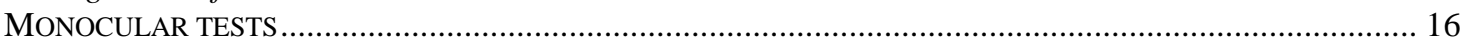

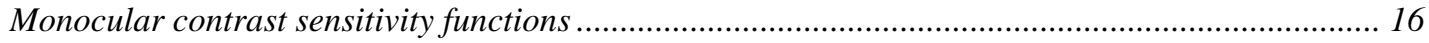

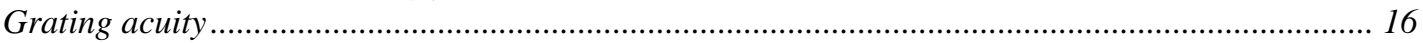

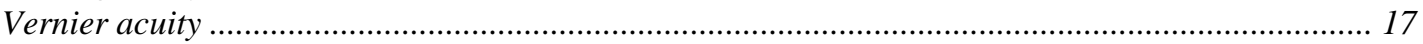

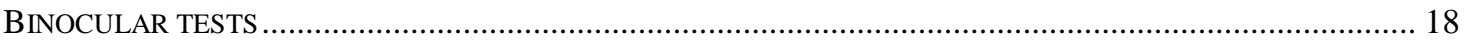

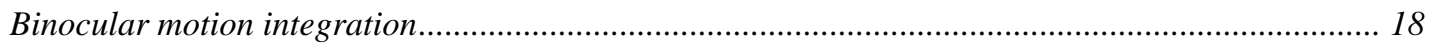

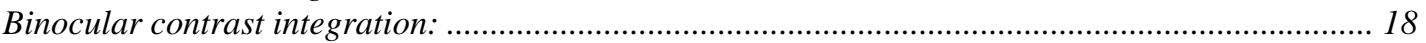

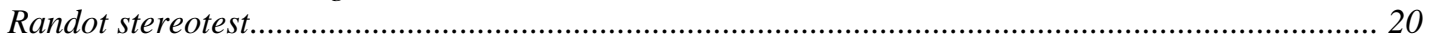

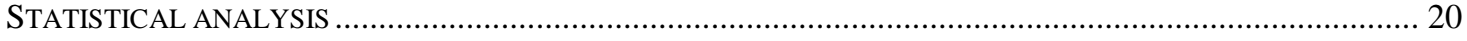

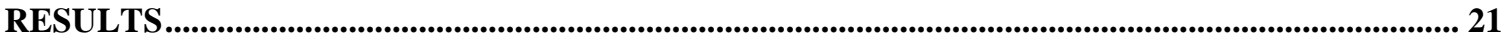

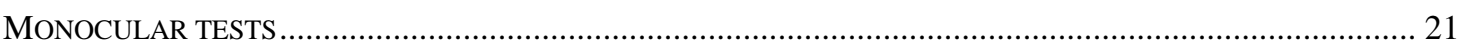

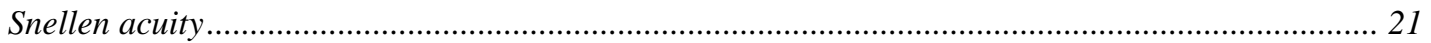

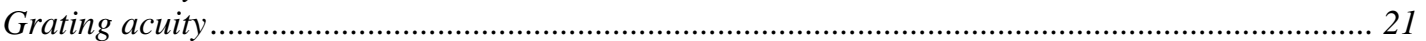

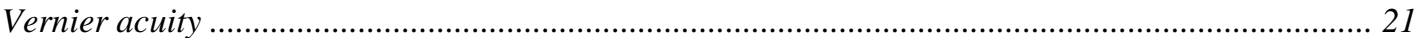

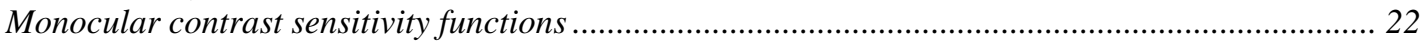

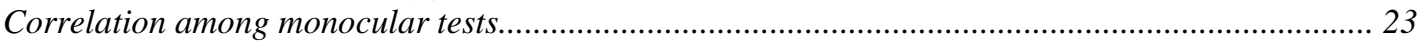

Comparison of the three monocular acuities ............................................................... 24

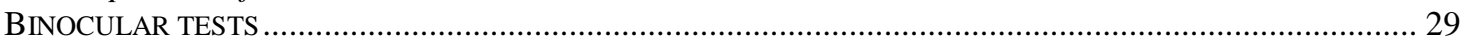

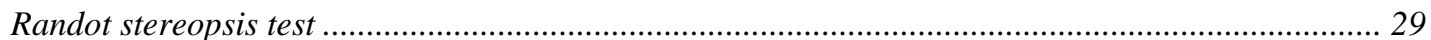

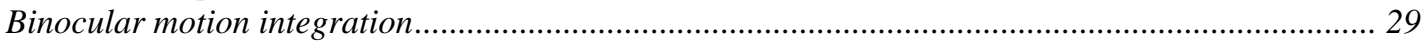

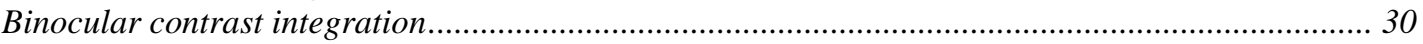

Binocular contrast integration in the fellow eye ............................................................ 30

Correlation between acuities using binocular and non-binocular sub groups ............................... 33

DISCUSSION...................................................................................................................................... 37

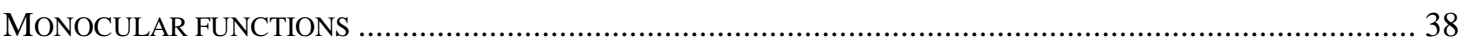

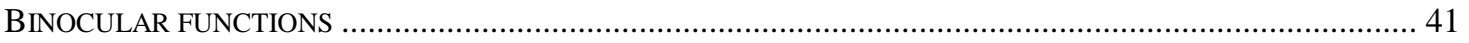

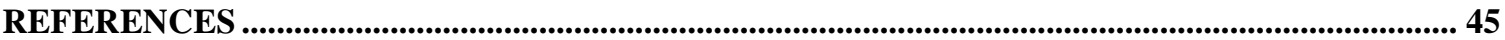

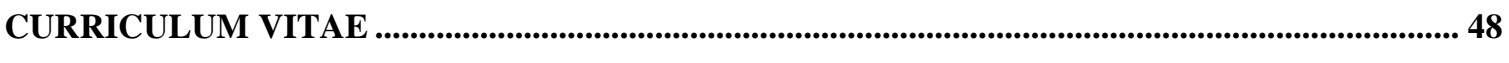




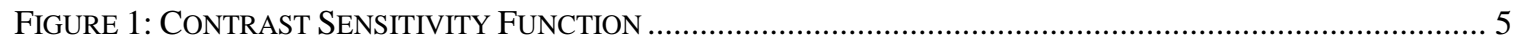

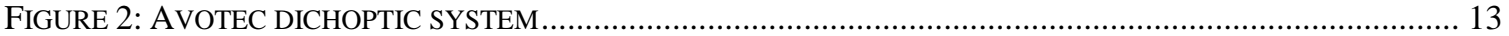

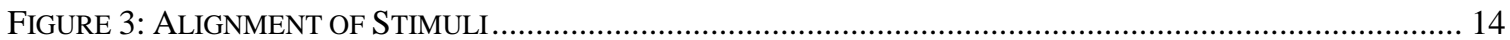

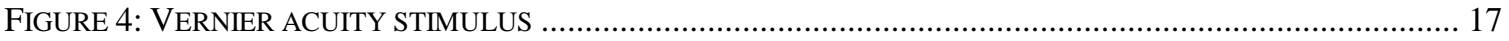

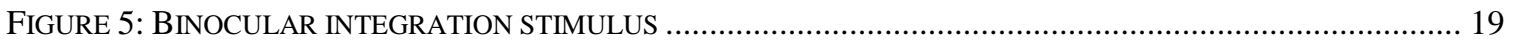

FIGURE 6: GRATING ACUITY FOR THREE CATEGORIES OF SUBJECTS (MINUTES OF VISUAL ANGLE); ERROR

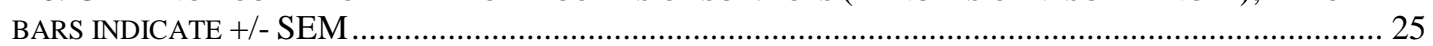

FIGURE 7: GRATING ACUITY FOR THREE SUBJECT CATEGORIES OF SUBJECTS (MINUTES OF VISUAL ANGLE),

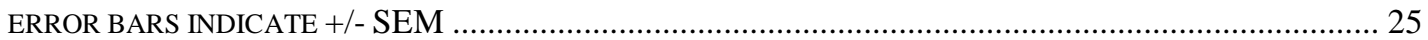

FIGURE 8: VERNIER ACUITY OF THREE CATEGORIES OF SUBJECTS MEASURED IN MINUTES, ERROR BARS

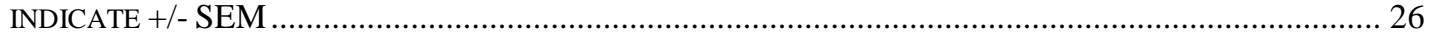

FIGURE 9: CONTRAST SENSITIVITY FUNCTION FOR THE WEAK EYE FOR THE THREE SUBJECT GROUPS, ERROR

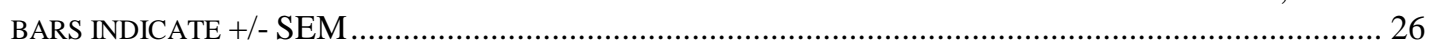

FIGURE 10: CONTRAST SENSITIVITY FUNCTION FOR THE FELLOW EYE IN THREE SUBGROUPS OF SUBJECTS,

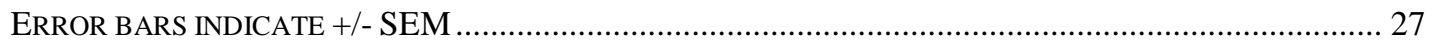

FIGURE 11: BIVARIATE FIT OF GRATING ACUITY (ARC-MINUTES) BY SNELLEN ACUITY (MAR), (BLUE DOTS= CONTROL SUBJECTS, RED DOTS= STRABISMICS, GREEN DOTS = ANISOMETROPICS $)$....................... 27

FIGURE 12: BIVARIATE FIT OF VERNIER ACUITY (ARC-MINUTES) BY SNELLEN ACUITY (MAR) (BLUE DOTS=

CONTROL SUBJECTS, RED DOTS = STRABISMICS, GREEN DOTS = ANISOMETROPICS) ...................... 28

FIGURE 13: BIVARIATE FIT OF VERNIER ACUITY (ARC-MINUTES) BY SNELLEN ACUITY (MAR) BASED ON

CLINICAL CLASSIFICATION. (RED = ANISOMETROPIC AMBLYOPES, GREEN = STRABISMIC AMBLYOPES) 28

FIGURE 14: BINOCULAR CONTRAST INTEGRATION (AVERAGE CORRECT) ACROSS THREE GROUPS OF SUBJECTS,

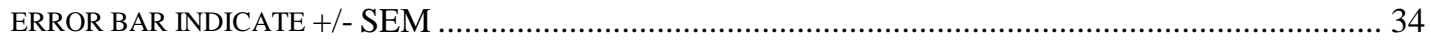

FIGURE 15: BINOCULAR CONTRAST INTEGRATION FOR THE FELLOW EYE ACROSS THREE GROUPS OF SUBJECTS,

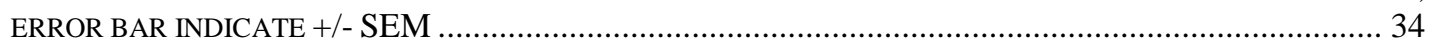

FIGURE 16: BINOCULAR CONTRAST INTEGRATION FOR THE FELLOW EYE ACROSS THREE GROUPS OF SUBJECTS,

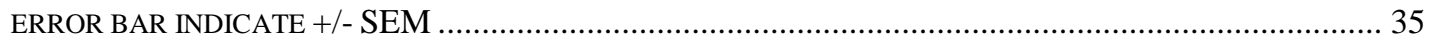

FIGURE 17: RANDOT STEREOSCOPIC TEST AVERAGE ACROSS THREE GROUPS OF SUBJECTS., ERROR BAR

INDICATE +/- SEM, ERROR BARS VERY SMALL AND HENCE MERGE WITH THE BARS. ....................... 35

FIGURE 18: BIVARIATE FIT OF SNELLEN ACUITY (MAR) BY GRATING ACUITY (ARC MINUTES) ...............36

FIGURE 19: BIVARIATE FIT OF SNELLEN ACUITY (MAR) BY VERNIER ACUITY (ARC MIN) ....................... 36

FIGURE 20: BIVARIATE FIT OF GRATING ACUITY (MAR) BY VERNIER ACUITY (ARC MINUTES) ................ 37 


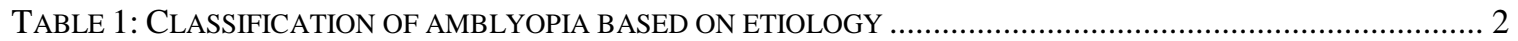

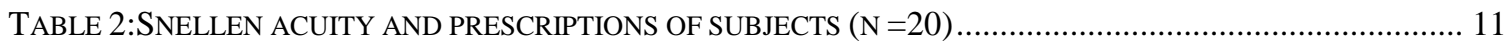

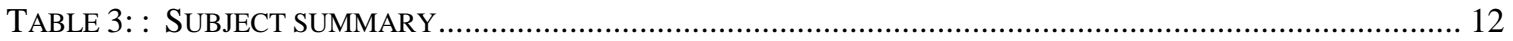

TABLE 4:: MEAN SNELLEN, GRATING, AND VERNIER ACUITY OF SUBJECTS ......................................... 22

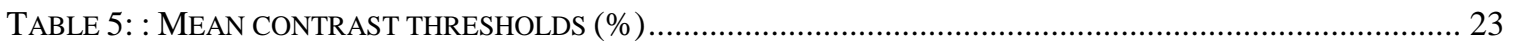

TABLE 6: BINOCULAR MOTION INTEGRATION (AVERAGE PERCENTAGE CORRECT TRIALS) .......................... 31

TABLE 7: BINOCULAR CONTRAST INTEGRATION (\%) AND RANDOT TEST ............................................. 31

TABLE 8: T VALUE AND P VALUES ON COMPARING AMBLYOPIC SUBGROUPS WITH CORRESPONDING NORMAL

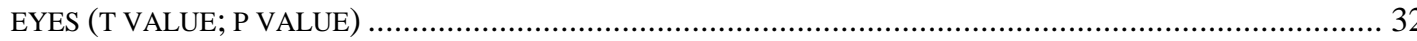

TABLE 9: ANOVA RESULTS FOR THE THREE ACUITIES. FOR FACTORS THE F RATIO AND P VALUES ARE SHOWN SEPARATED BY SEMI COLON (;). THE NON-SIGNIFICANT VALUES ARE SHOWN IN BLACK.......... 33 


\section{INTRODUCTION AND BACKGROUND}

\section{Definition of amblyopia}

Amblyopia is a developmental visual disorder defined usually as a monocular decrease in vision for which no obvious cause can be detected by physical examination of the eye and which in appropriate circumstances is correctable by therapeutic measures (Burian \& Noorden, 1980). The average incidence in the general population has been estimated in the range of $2-4 \%$. Amblyopia is commonly identified by a difference in visual acuity between the eyes by at least a factor of two (comparable to a 2-line difference on the eye chart). In common language this condition is sometimes also referred to as the lazy-eye disease.

\section{Mechanisms and types of amblyopia}

Three fundamental etiologies of amblyopia appear to exist, namely those caused by occlusion, strabismus and anisometropia. Strabismic amblyopia can be further subdivided based on the direction of deviation of eyes, as esotropia (deviation towards nose) and exotropia (deviation towards the temple). An etiologic classification of amblyopia is shown in Table 1. The fundamental mechanism in these etiologies is believed to involve two major factors: form vision deprivation and abnormal binocular interaction.

The scientific origin of the current explanations of amblyopia and development of vision in early life was laid by Hubel and Wiesel in early 1960s. They demonstrated in kittens that with the deprivation of monocular vision in the early periods of life, a great alteration in the balance of input from the two eyes to individual neurons in the striate visual cortex (V1) is observed (Hubel and Wiesel, 1964). This period is known as the "critical period" and is typically three weeks to three months in kittens (Daw, 1998). The time period of normal visual development is correlated with the "critical period". 
Occlusion of the eye by eyelid closure, in animals, reduces approximately $90 \%$ of light reaching to the eye, and prevents the formation of sharply focused retinal image (Crawford and Marc, 1976). In anisometropia, which is caused by unilateral unequal refractive error (usually hypermetropia), an unrestricted amount of light reaches the retina but the images formed at the retina are blurred, i.e. form vision is impaired. Likewise, in strabismus, focusing of the foveal image in the deviated eye is determined by the accommodative requirement of the other fixating eye, with the result that images on the fovea of the deviated eye will be defocused much of the time. This situation also causes form vision deprivation.

Animal studies have also demonstrated competitive binocular interactions at the cellular level. Hubel and Weisel also sutured both the eyes of some animals closed. If amblyopia was simply due to disuse, closing both eyes should double the impairment. To their great surprise, the cortical cells responded rather normally. Evidently, the results of monocular closure had been due to some kind of competition between the neurons from the two eyes consequently leading to suppression of one. Consistently, the binocularity of primary visual cortex is also changed and often lost in human amblyopes, especially in strabismic amblyopes. In the majority of cases of strabismus in humans, diplopia and confusion in early life (due to lack of retinal correspondence) is thought to be avoided through suppression of the visual inputs from one eye. This competitive, inhibitory effect would occur only in those portions of the visual pathways in which binocular interaction is anatomically possible, i.e. the striate cortex and other visual areas. The loss in binocularity is demonstrated psychophysically by losses in many binocular functions including stereoacuity and binocular summation effects. In anisometropes, the binocularity loss shows a more restricted, but interesting pattern. Losses occur mostly for the higher spatial frequencies (reduced due to blur) in the central visual field, while binocularity is largely intact in peripheral visual fields (Pardhan and Whitaker, 2000).

Table 1: Classification of amblyopia based on etiology

\begin{tabular}{|c|c|c|}
\hline Cause & Effect & \\
\hline
\end{tabular}




\begin{tabular}{|c|c|c|}
\hline & Form Vision deprivation & $\begin{array}{c}\text { Abnormal binocular } \\
\text { interaction }\end{array}$ \\
\hline Strabismus & + & + \\
\hline Anisometropia & + & + \\
\hline $\begin{array}{c}\text { Unilateral occlusion (cataract, } \\
\text { corneal opacity, etc.) }\end{array}$ & + & - \\
\hline Bilateral occlusion & + & - \\
\hline Bilateral High hypermetropia & + & - \\
\hline Congenital nystagmus & + & + \\
\hline
\end{tabular}

Source: (Noorden, 1977), table 1 page 109.

There is a modest amount of literature devoted to understanding the neural substrates of amblyopia. In primates and humans, the weight of evidence suggests that neural effects of strabismus and anisometropia are expressed primarily in the cortex, while the peripheral optical and neural mechanisms are essentially unaffected (Hess, 2001). Most studies of the retina of amblyopic animals conclude that there is no change at this level (Hendrickson et al., 1987;Delint et al., 1998). Furthermore, the spatial and temporal response properties of lateral geniculate nucleus (LGN), in which afferents from two eyes remain segregated, are largely normal in amblyopic monkeys (Movshon et al., 1987). However, in the primary visual cortex (V1), binocular and spatial vision is significantly decreased in amblyopes (Crewther and Crewther, 1990;Kumagami et al., 2000) Nevertheless, the site of deficit is probably not limited to the extent of V1. In a quantitative study on monkeys, Kiorpes et al. (1998) demonstrated that the spatial visual anomalies in primary visual cortex, cannot explain the full range of visual deficits in amblyopia. They suggested the possibility of more profound single cell spatial anomalies beyond V1 in primates. A similar situation is likely to exist for humans with amblyopia. For example, in a recent fMRI study of ten strabismics Barnes and colleagues further tested this possibility and found evidence of abnormal function in many visual areas, including V1 (Barnes et al., 2001). They further suggested that, because of the abundance of feedback connections from extra-striate cortex into $\mathrm{V} 1$, it remains a possibility that the lack of response from V1 is due to a primary abnormality in extra-striate cortex. In another recent fMRI study, amblyopic subjects demonstrated decreased activation in the 
fusiform gyrus, further supporting the idea that the extent of deficit goes beyond V1 (Lerner et al., 2003).

\section{Common techniques used to study the visual properties in amblyopia}

Several popular methodologies exist to study the visual cortex in amblyopes. They include studies at the cellular level with neurophysiological techniques, studies at a more global population level by means of functional MRI and behavioral analysis through psychophysical testing. In addition neuropsychological studies (ERPs) are also performed in humans. Primarily, the neurophysiological studies are conducted on laboratory animals like cats and monkeys while the fMRI and psychological testing is performed on human subjects. All these methods of testing compliment each other. The neurophysiological studies provide data at a more cellular level, which cannot be done on humans due to their invasiveness. However, applying animal data to humans can be challenging due to physiological differences between species and the difficulty of interpreting animal perception. Nevertheless, these studies do provide a critical framework for designing the experiments for human testing. Functional MRI studies on the other hand are usually performed on humans utilizing the Blood Oxygen Level Dependent (BOLD) effect. Such studies are found to be extremely helpful in localizing the abnormalities in activation in the visual and associated visual areas. This method is limited by its temporal resolution and is also expensive. The psychophysical testing is directed towards important behavioral aspects. It measures human perception through the presentation of welldefined stimuli, and careful recording of perceptual response.

\section{The human contrast sensitivity function}

Contrast sensitivity is the ability to differentiate between a sinusoidal grating with luminance and contrast characteristics and a background with the same mean luminance. It is one of the most examined aspects of visual performance as it offers a good measure of the functional visual range. The contrast sensitivity function (CSF) is a plot of contrast 
sensitivity (reciprocal of threshold percent contrast) for all spatial frequencies as shown in Figure 1. A contrast sensitivity assessment procedure consists of presenting the observer with a sine-wave grating target of a given spatial frequency (i.e., the number of sinusoidal luminance cycles per degree of visual angle). The contrast of the target grating is then varied while the observer's contrast detection threshold is determined.

Typically, contrast thresholds of this sort are collected using vertically oriented sine-wave gratings varying in spatial frequency in cycles per degree of visual angle. The $\mathrm{X}$ and $\mathrm{y}$ axes are plotted in log units. The typical human contrast sensitivity function peaks between 2 and 5 cycles/degree (cpd). The CSF shows a reduction in sensitivity for both low and high spatial frequencies, suggesting many important features. The highfrequency cut-off in sensitivity reveals that there is a finite limit to the visual system's ability to resolve details. At around 40-50 cpd the gratings cannot be resolved even at 100 percent contrast. This acuity is referred as the grating acuity. There are two important explanations for this limitation. Firstly, any optical system including the eye has a high frequency limitation because of inherent optical aberration and secondly, the packing density of retinal photoreceptors limits the resolution of the spatial frequencies. This visual limitation is extended at the cortical level too. There is a large area devoted to the fovea itself and the representation in fovea is magnified at the cortical level, which in turn maximizes resolution. The magnification limits of cortex also contribute to the restricted grating acuity.

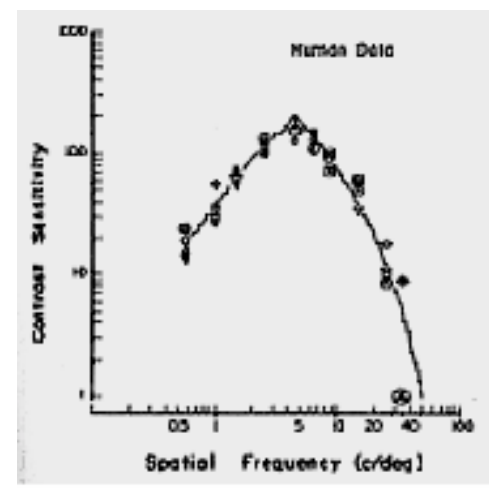

Figure 1: (Graph from DeValois \& DeValois (1988) Spatial Vision.

Oxford: Oxford University Press)

Figure 1: Contrast Sensitivity Function 


\section{Contrast sensitivity function in amblyopia}

In amblyopia, the contrast sensitivity function is usually described as being depressed, especially at higher spatial frequencies, with the peak sensitivities shifted to lower spatial frequencies (Gstalder \& Green, 1971). Among the subtypes, subtle differences in the CSF are present. The anisometropes are more likely to suffer additional deficits at lower spatial frequencies as a linear function of depth of amblyopia (Sjostrand, 1981;Harwerth and Levi, 1977). Strabismics on the other hand have been shown to have more variability in the severity of CSF loss, although the primary contrast sensitvity deficit is in the high spatial frequency range (McKee, Levi, \& Movshon, 2003).

\section{Differences in the visual abnormalities of the two types of amblyopia}

A considerable amount of research has been done to differentiate the visual performance of strabismic and anisometropic amblyopia. The motivation often is to identify and understand the pathogenesis of amblyopia. In fact, it is analogous to the "which came first, the chicken or the egg?" situation. Is amblyopia a consequence of strabismus/ anisometropia, or does is serve as the cause itself to its subtypes? A recent and very large study was conducted on a group of 427 amblyopes and 68 normal subjects. They demonstrated moderate loss of visual acuity in strabismics and anisometropes combined with worse than normal contrast sensitivity (McKee, Levi, \& Movshon, 2003). Binocular vision was also taken into consideration because amblyopia is considered to be a developmental disorder. If subjects with strabismus were also strabismics when they were young then their binocular vision would likely have been disrupted by uncorrelated binocular stimulation. On the other hand, anisometropic subjects might have experienced degraded visual input, but the inputs from the two eyes would have been concordant, at least at low spatial frequencies, and binocular vision might have developed relatively normally. The authors found that only $10 \%$ of their strabismics passed the binocular motion integration test, as compared to 100\% normals and 35\% anisometropes. They inferred that two associated conditions determine the pattern of visual deficit - the loss of 
binocularity and the reduced resolution. Thus, the strabismic and anisometropic forms of amblyopia form a 'spectrum' based on the degree of loss of the above two conditions. Consequently, in practice many subjects display an overlapping 'array' of loss of psychophysical functions.

Consistent with the above study, Kiorpes et al, demonstrated similar findings in their experimentally created strabismic and anisometropic monkeys (Kiorpes et al., 1998;Kiorpes and McKee, 1999). They found that all amblyopic monkeys showed a substantial reduction in cortical binocularity, with strabismic amblyopes having the smallest number of binocularity activated neurons. Similar to McKee and colleagues, they hypothesized that it is the severity of binocular loss and not the etiology of the visual losses that seems to predict the nature of the physiological changes in amblyopia. In other words, the degree of binocularity loss may at least partially predict the degree of abnormality on monocular tasks.

Another source of evidence that strabismus may cause a different type of amblyopia than anisometropia is derived from the monocular position acuity tasks. Vernier acuity is a common example of a position acuity task. It is the ability to perceive a small misalignment (offset) between two parallel lines and requires very precise positional information. The normal human eye is very sensitive to the Vernier offset. Sensitivity is on the order of 0.1 ' (5-10 arc seconds) of visual angle (Kiorpes and McKee, 1999b). This sensitivity implies that normal vision is capable of discrimination of offsets even smaller than a single retinal cone diameter (Westheimer, 1979). For this reason the Vernier acuity is often referred to as a "hyperacuity". The losses in these tasks are larger in strabismics as compared to anisometropes. In anisometropes the losses can be predicted from their loss in grating acuity while in strabismics the losses are much larger than would be predicted by linearly scaling the grating acuity to the distances involved in the position acuity (Levi and Klein, 1982c). This indicates that some additional mechanisms are involved in strabismics which lead to relatively greater loss in Vernier acuities. This reason for this additional deficit has been a matter of debate. Three possible hypotheses have tried to explain this phenomenon: a) the size and shape of receptive fields are altered in the cortex, b) the density of cortical receptive fields are altered, i.e. 
"undersampling", and c) spatial disarray in the location of filters, which means that the number of cortical filters is normal but, topographical information is incorrect or jittered. All three theories alone are unable to explain the whole spectrum of Vernier acuity abnormalities. However, in general they suggest that abnormal 'noise' (either due to undersampling or due to jitter) arises in cortex, probably higher than primary visual cortex (V1) and not at the earlier retinal and subcortical visual pathways. In addition, they imply that measurement of Vernier acuity in subjects provides a measure of the loss at the higher visual pathways.

A related symptom especially seen in strabismic amblyopes is called "crowding". This is a phenomenon in which visual acuity measured using a multiple-letter chart is worse than acuity measured by presenting single letters (Asper et al., 2000). This is common in amblyopes and is thought to be due to a combination of contour interaction, fixational eye movements and attentional factors. Amblyopic patients can read the first and last letters on the line, but not the center letters. Isolation of individual letters improves measured visual acuity in amblyopia. In summary, the above abnormalities support the idea that the strabismus may cause a different type of amblyopia. They suggest that, in general, strabismics shows greater spatial localization impairments and more severe loss of binocular integration.

\section{Binocular integration in amblyopia}

Binocular integration of the image formed in each eye is known to result in several distinct visual abilities. Probably the most significant benefit of binocular vision is stereopsis which is the pinnacle of binocular fusion. Stereopsis is the perception of depth that is produced by binocular retinal disparity. In general, stereopsis is almost universally reduced, often absent in both types of amblyopia (Levi et al, 1979). Specifically, stereopsis was measured in anisometropes as a function of spatial frequency, and found to be normal at low spatial frequencies, subnormal at intermediate spatial frequencies, and unmeasurable at higher spatial frequencies. In strabismus, the loss in 
stereoacuity is more profound at all the spatial frequencies because of greater loss in binocular neurons.

There is another more subtle benefit of binocular vision which is known as binocular contrast summation. This is the process by which binocular vision is enhanced over what would be expected from monocular vision. It has been shown in normal observers that the CSF is improved in one eye with sub-threshold or threshold stimulation in other eye. Pardhan and Gilchrist measured both monocular and binocular contrast sensitivity functions for three strabismics and anisometropic amblyopic subjects (Pardhan and Gilchrist, 1992). They used these CSFs to compute ratios describing the relative improvement or decrement in the CSF from using both eyes rather that only one (binocular/non-amblyopic). They found that anisometropic amblyopes showed greater binocular summation than strabismic amblyopes, and that summation effects were greatest at low spatial frequencies $(0.5 \mathrm{cpd})$.

An opposite phenomenon is known as binocular contrast inhibition. If conflicting supra-threshold stimulus is presented to the fellow eye, the contrast sensitivity function threshold gets elevated as a result of binocular inhibition (Legge, 1979). Interestingly, in amblyopes, the binocular inhibition is usually found to be intact. Levi et al. showed that both strabismic and anisometropic amblyopes exhibit the same degree of contrast threshold elevation as normals when the fellow eye is stimulated, with a supra-threshold grating coincident with measuring contrast sensitivity in the amblyopic eye (Levi et al., 1979). These psychophysical findings suggest that binocular interactions in the amblyopic visual system are abnormal. Specifically, binocular summation is impaired or absent, but binocular inhibition is intact.

Motion perception is another phenomenon which can be associated with binocular vision. Arguments have been made that while fine pattern perception (high spatial frequencies) is affected in amblyopes, the motion pathway is not affected (Chung and Levi, 1997). Thus it may be that residual binocular integration ability exists when tested with this relatively unaffected function of motion sensitivity. With this motivation, 
McKee and colleagues used binocular motion integration as a measure of binocularity to study the differences in the two subtypes of amblyopia (McKee et al., 2003). They used the binocular motion integration model proposed by (Shadlen and Carney, 1986a). They found significant deficits in binocular motion integration in amblyopia subjects. Only $10 \%$ of strabismics and $35 \%$ of anisometropes, as compared to $100 \%$ of normal subjects, passed the binocular motion integration test. They further questioned if binocularity predicts performance on Vernier acuity. By comparing the Vernier acuity of the binocular group with a matched subset of non-binocular observers, they found a highly significant difference $(p<.001)$ between them. Thus, they proposed that the differences in Vernier acuity noted in anisometropes and strabismics can be predicted by the differences in binocular function.

The current proposed project includes an attempt to replicate the conclusions of the above study. In addition, we will introduce another parameter: binocular contrast integration. We will determine the binocularity of amblyopic subjects both by binocular summation/inhibition and motion integration and correlate them with the Vernier and grating acuity. This will help us to better understand the pathogenesis of the two types of amblyopia and will contribute to our lab's long term goal of guiding application of potential therapies in a more definite manner.

\section{METHODS}

\section{General Methods}

\section{Subjects}

This study examined 20 subjects, including 7 control, 7 anisometropic and 6 strabismic observers (19-35 years of age) (Table 1 and 2). They were recruited by advertisements in surrounding regions of West Virginia, Pennsylvania and Maryland. All subjects provided informed consent (WVU Protocol \#14788). Any subject with known or suspected neurological conditions was excluded from the study. Most subjects with amblyopia have a history of patch treatment during childhood, i.e., a patch was worn to 
cover the dominant eye (which is called the fellow eye), and thus force the subject to use the weak eye for daily visual tasks for a portion of each day. Nevertheless, the presence of amblyopia at the time of testing shows that the deficit was never completely reversed.

In Caucasian populations of strabismic subjects, there is often a greater prevalence of subjects with inward eye deviations (esotropia) than outward deviations (exotropia), and our sample was no exception. The direction of strabismic deviation was measured with the alternate cover test, and amount of deviation was determined with prism testing. Our subjects had the range of deviation from 0-12 D. All of the amblyopic subjects showed reduced visual acuity in their weak eye (Table 2).

All subjects completed an ophthalmologic exam to confirm diagnosis that includes tests of ocular motility, dilation, fundus exam, autorefraction, Snellen visual acuity, Worth 4-dot, Randot stereopsis, Ishiara color plates, and Lighthouse contrast charts.

Table 2:Snellen acuity and prescriptions of subjects $(n=20)$

\begin{tabular}{|c|c|c|c|c|c|c|c|}
\hline Subject & $\begin{array}{c}\text { Catego } \\
\text { ry }\end{array}$ & $\begin{array}{c}\text { Weak } \\
\text { eye* }\end{array}$ & OS & OD & $\begin{array}{c}\text { Pris } \\
\mathbf{m}\end{array}$ & $\begin{array}{c}\text { Refraction } \\
\text { OS }\end{array}$ & Refraction OD \\
\hline NC & Normal & Left & $20 / 20$ & $20 / 20$ & - & $-0.25+0.50 \times 154^{\circ}$ & 00 \\
\hline CA & Normal & Right & $20 / 16$ & $20 / 20$ & - & $-2.25+0.50 \times 179^{\circ}$ & $-3.75+0.75 \times 178^{\circ}$ \\
\hline PF & Normal & Right & $20 / 20$ & $20 / 20$ & - & 00 & 00 \\
\hline AW & Normal & Left & $20 / 16$ & $20 / 16$ & - & $-0.25+0.25 \times 39^{\circ}$ & 00 \\
\hline DW & Normal & Right & $20 / 16$ & $20 / 20$ & - & 00 & 00 \\
\hline RL & Normal & Left & $20 / 20$ & $20 / 16$ & - & 0.50 & 0.50 \\
\hline LRW & Normal & Right & $20 / 20$ & $20 / 25$ & - & $-1.75+1.75 \times 166^{\circ}$ & $-1.50+1.25 \times 175^{\circ}$ \\
\hline DS & Strab & Left & $20 / 25$ & $20 / 16$ & 6 & 00 & 00 \\
\hline MY & Strab & Right & $20 / 25$ & $20 / 50$ & 8 & $0.25+0.50 \times 162^{\circ}$ & $0.25+0.50 \times 2^{\circ}$ \\
\hline CL & Strab & Left & $20 / 40$ & $20 / 20$ & 4 & $2.25+1.25 \times 88^{\circ}$ & $2.50+3.50 \times 95^{\circ}$ \\
\hline KH & Strab & Right & $20 / 16$ & $20 / 32$ & 6 & $2.50+0.50 \times 44^{\circ}$ & $2.50+3.50 \times 98^{\circ}$ \\
\hline BC & Strab & Left & $20 / 160$ & $20 / 20$ & 12 & $1.00+0.50 \times 118^{\circ}$ & $1.75+1.00 \times 71^{\circ}$ \\
\hline SL & Strab & Left & $20 / 25$ & $20 / 25$ & 0 & $-1.00+1.00 \times 171^{\circ}$ & $-100+0.50 \times 15^{\circ}$ \\
\hline JL & Aniso & Right & $20 / 25$ & $20 / 50$ & - & $2.75+0.50 \times 11^{\circ}$ & $1.00+0.50 \times 64^{\circ}$ \\
\hline LW & Aniso & Left & $63 / 20$ & $20 / 16$ & - & $0.00+0.25 \times 37^{\circ}$ & $2.00+0.75 \times 101^{\circ}$ \\
\hline JW & Aniso & Left & $20 / 32$ & $20 / 20$ & - & $-0.25+0.25 \times 71^{\circ}$ & $2.00+0.75 \times 101^{\circ}$ \\
\hline AG & Aniso & Left & $63 / 20$ & $20 / 20$ & - & $-0.75+0.50 \times 32^{\circ}$ & $1.75+2.50 \times 145^{\circ}$ \\
\hline RW & Aniso & Right & $20 / 16$ & $20 / 32$ & - & $3.50+0.50 \times 116^{\circ}$ & $-1.00+0.25 \times 109^{\circ}$ \\
\hline JM & Aniso & Right & $20 / 25$ & $20 / 20$ & - & $3.25+1.00 \times 27^{\circ}$ & $2.00+0.75 \times 124^{\circ}$ \\
\hline KT & Aniso & Right & $20 / 40$ & $20 / 160$ & - & & $\mathrm{N} / \mathrm{A}$ \\
\hline & & & & & & & \\
\hline
\end{tabular}


- For normal subjects we will use the terminology "dominant" and "non-dominant" eye. However for amblyopes will use the term "fellow" and "weak" eye. The non dominant eye in normals is assigned based on which eye has lower Snellen acuity. If Snellen acuity is same in both eyes then grating acuity was taken as the criteria.

Table 3: : Subject summary

\begin{tabular}{|l|c|c|c|c|c|}
\hline & N & Age & $\begin{array}{c}\text { Years of } \\
\text { education }\end{array}$ & $\begin{array}{c}\text { Near acuity } \\
\text { normal or fellow }\end{array}$ & $\begin{array}{c}\text { Near acuity } \\
\text { ambly. }\end{array}$ \\
\hline Control & 7 & 25.1 & 13.7 & 18 & - \\
\hline Strabismics & 6 & 26.3 & 13.5 & 20 & $61^{* \wedge}$ \\
\hline Anisometropes & 7 & 28 & 14.9 & 23 & $61^{* \wedge}$ \\
\hline
\end{tabular}

* Amblyopic eye significantly different from worst eye of control subjects.

$\wedge$ Amblyopic eye significantly different from fellow eye.

\section{Apparatus and procedure}

All the experiments were conducted in darkened rooms and all the visual display hardware devices were calibrated to ensure predictable, linear outputs. Binocular motion and contrast integration experiments were done using an Avotec dichoptic system. This sophisticated dichoptic device is described in the following section. Thirdly, the monocular contrast sensitivity experiment was also administered using the Avotec system, the stimulus was shown only to the tested eye and the other eye was shown an isoluminent grey screen. The rationale behind doing this monocular test in the dichoptic setting is because it is known that amblyopic eye function is affected by whether or not the fellow eye is open (with or without visible light) or occluded. We avoided occlusion of the eye by our dichoptic setup.

Vernier and grating acuity tests were administered on high resolution CRT screens because a large viewing distance is required $(5.87 \mathrm{~m})$. Subjects were tested (with their normal optical correction) with one eye covered with a translucent patch, which also avoids complete occlusion of that eye. Finally, all tests included practice trials to ensure that the task was understood, and the stimuli were visible. 


\section{Dichoptic visual stimulation}

The stimuli were presented with dual fiberoptic periscopes (Avotec, Inc., SV 4021 fiber optic visual system) with built-in optical correction, binocular eye tracking, and adequate resolution. The dichoptic arrangement is shown schematically in Figure 2. This system allows the subject to view images which are generated at the video interface, located at the control station using the Macintosh computer. This dichoptic arrangement offered considerable flexibility for experiments as the stimuli in both the eyes can be independently controlled. The system involves video-based eye tracking so that movement in the eyes can be quantitatively monitored. This tracking system also provides a real-time image of each of the subjects' eyes, which enables the experimenter to perform specialized observations like the cover test

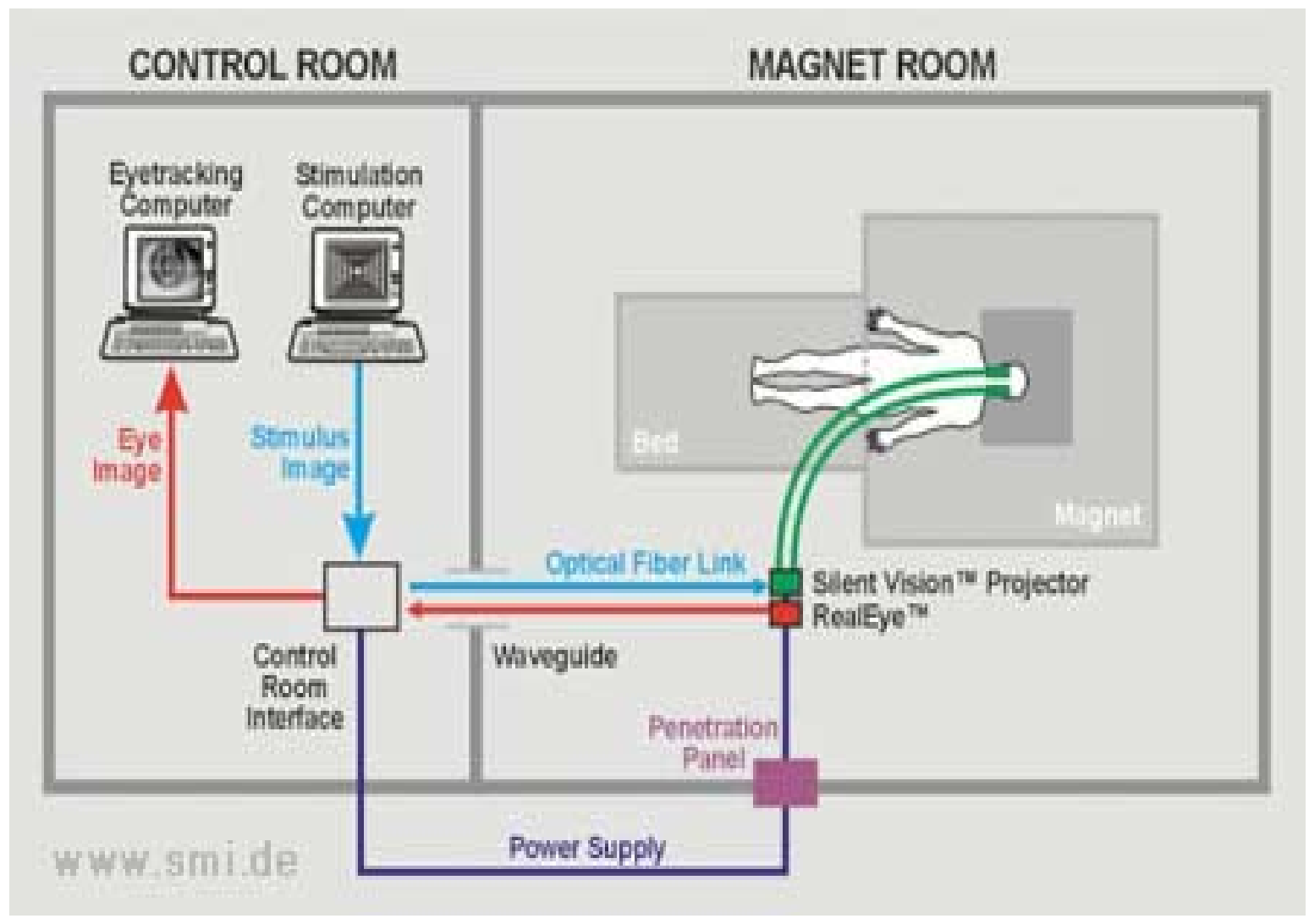

Figure 2: Avotec dichoptic system 


\section{Alignment of stimuli}

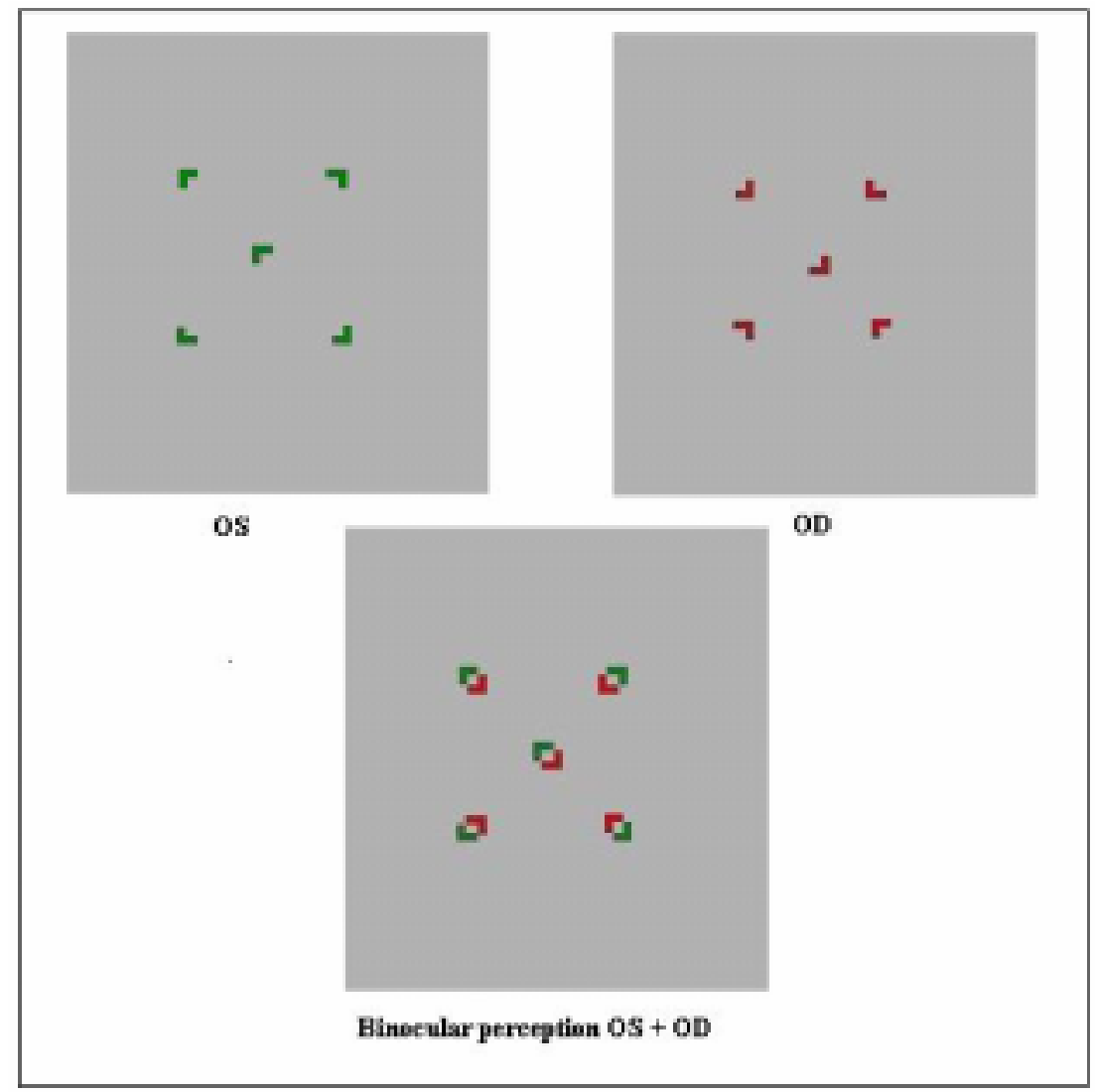

Figure 3

Figure 3: Alignment of Stimuli

For the two tests that require binocular visual stimuli (binocular contrast integration and binocular motion integration) we need methods that ensure correct alignment of stimuli in the two eyes. In addition, the fixation points were shown to both eyes and we took care to align them in corresponding retinal regions. This has the advantage of aiding overall fixation stability, and supports more natural retinal correspondence.

In order to align the stimuli and fixation points in the two eyes we relied on the fact that eye piece positions can be controlled independently by Avotec hardware. In addition, we can adjust the location of stimuli with our presentation software for each eye. During the alignment procedure, the subjects viewed red and green angles (nonius cues) comprised of separate pattern elements shown to each eye that form a simple shape 
(square) when fused. We used multiple cues located at the center of gaze, as well as in the periphery. Green shapes were presented to left eye and red shapes are presented to the right eye (Figure 3). As expected, some amblyopic subjects who possessed constant suppression of the fovea were never able to achieve fusion of the central cue.

We took a stepwise approach to align the stimulus. We began by adjusting the eye pieces under the guidance of eye tracking cameras, in order to bring each eye to approximately the center of the screen. Subjects' perception of monocular and binocular alignment of the nonius cue was determined, and based on these perceptual reports fine adjustment of the stimulus was performed with software. This procedure was repeated until the stimuli were aligned as closely as possible.

The second part of the alignment process involved alternate cover testing. The principle of this test is that when one eye is covered, it assumes a resting position as there is no visual input to guide fixation. When the cover is removed the eye moves from the resting position in order to take on fixation. In our setting, the experimenter started by switching-off one of the screens (screen turned black). This process was alternated for both the eyes. In strabismic and anisometropic subjects heterotropia or heterophoria is sometimes present depending on the severity. The deviation (if present) was noted in the eye tracking monitors. Based on the degree and direction of deviation the stimulus in the weak eye was moved via software control. This process is analogous to using prisms as part of the clinical cover test. The best attempt was made to reach the 'end point' where no movement occurs in the eyes. This end point is the point where stimulus location effectively compensates for the eye deviation.

The resulting stimulus locations were noted and compared to those derived from the perceptual reports described previously. In most cases the locations of stimuli were similar to the previous values. This implies that alignment by cover test and by visual perception was very similar. Thus, at this particular value of alignment the stimulus is presented at the fovea. If the cover test value was different than the perceived value, a possibility of anomalous retinal correspondence was noted. The anomalous retinal correspondence if suspected was confirmed with Bagolini glasses and after-image test. 


\section{Monocular tests}

We included four monocular tests in this study: the monocular contrast sensitivity test, grating acuity, Vernier acuity and Snellen acuity. The Snellen test was done at the Department of Ophthalmology, West Virginia University Hospitals as part of a clinical exam. The remaining tests were performed in the laboratory setting.

\section{Monocular contrast sensitivity functions}

Each eye was tested separately in the dichoptic setup. In this way monocular functions were assessed as the non-tested eye viewed a mean level gray screen. Each trial lasted 2.5 seconds. The preparation time, stimulus presentation time and response accept time were 500, 200 and $1800 \mathrm{msec}$ respectively. A central cross was used as a fixation point. For each trial, the subject saw two temporally sequenced screens, one of which contained a vertical sinusoidal grating (subtending 8 degrees of visual angle). The subject was required to identify the epoch that included the grating; even if the subject needed to guess (the two-alternative forced choice paradigm, 2-AFC). A 2down-1up staircase procedure was used to approach the contrast detection threshold (71\%) at each of three spatial frequencies $(1.0,2.0$ and $4.0 \mathrm{cpd})$. The threshold data thus obtained were also used to compute sub-threshold and supra-threshold stimuli for other experiments. Specifically, we used these calculated subs- and supra- threshold values for the administration of binocular contrast integration.

\section{Grating acuity}

The stimulus display consisted of a vertical sinusoidal grating generated on a high resolution CRT monitor (Hitachi super scan 812). The non-tested eye was occluded by a translucent patch. The weaker eye was always tested following the fellow eye. We measured the grating acuity with high contrast (80\%) vertical sinusoidal grating, viewed at 5.87 meters. Grating contrast was ramped-on over $200 \mathrm{msec}$ and after a plateau of 500 msec, was ramped-off over $200 \mathrm{msec}$. The spatial frequency was varied by a staircase 
procedure that increased spatial frequency following one correct response and decreased spatial frequency after one incorrect response. Approximately one third of trials were blanks. The staircase was terminated after seven reversals. The acuity threshold was taken as the geometric mean of the last four reversals. No feedback was provided.

\section{Vernier acuity}

The high resolution CRT monitor was used for this experiment. The stimulus consisted of five high-contrast (90\%) offset pairs of horizontal lines, each $2.5 \mathrm{~mm}$ wide and $15 \mathrm{~cm}$ long $(7.5 \mathrm{~cm}$ each half) separated vertically by $2.5 \mathrm{~cm}$. To obtain sub-pixel offsets, the luminance profile of the lines was dithered. The stimuli were ramped on over $200 \mathrm{msec}$, and after $500 \mathrm{msec}$ plateau, were ramped off over $200 \mathrm{msec}$. Each test began with an adjustment procedure in which the subject increased the offset until the left side was visibly higher or lower than the right side. The mean offset obtained from four adjustments (two up and two down) was used as a starting step size for a forced-choice staircase method. The observer's task was to indicate whether the offset was up or down as compared to left side, on each trial by pressing one of two response buttons. In subsequent trials the step size is reduced after a correct answer and is increased after an error. Feedback was also provided. We estimated Vernier threshold as the average test reversal.

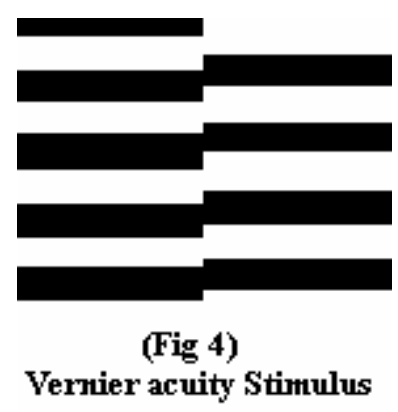

Figure 4: Vernier acuity stimulus 


\section{Binocular tests}

We included three binocular tests in our analysis, namely binocular motion integration, binocular contrast integration and the randot stereopsis test. The randot stereopsis test was done at the Department of Ophthalmology, West Virginia University Hospitals as a part of the clinical exam. The remaining tests were performed in the laboratory setting.

\section{Binocular motion integration}

The stimulus was based on that described by Carney and Shadlen (Carney and Shadlen, 1993). The experiment was conducted using the Avotec dichoptic system. Each eye viewed a vertical sinusoidal grating patch whose contrast was modulated sinusoidally at $2 \mathrm{~Hz}$. The stimuli in two eyes were spatially and temporally out of phase by 90 degrees to each other. The direction of phase shifts produces an illusion in which the binocular summed signal appeared to move left or right. The contrast used in one eye was $65 \%$. The subject has the flexibility to increase or decrease contrast so that the perceived contrast was approximately same in both eyes. To ensure appropriate alignment, the nonius cues were shown between trials. Once the nonius cues are aligned, the observers were given 20 motion trials in which they saw the matched dichoptic stimuli for 2 seconds, and judged the direction of movement. The preparation time and show times were 500 and $2000 \mathrm{msec}$, respectively. Feedback was provided after each trial. Five blocks of 20 trials were used to test five spatial frequencies: $0.312,0.625,1.25,2.5$ and $5.0 \mathrm{cpd}$.

\section{Binocular contrast integration:}


The experiment was conducted using the Avotec equipment so as to achieve dichotic viewing conditions. To ensure proper alignment the five nonius cues were shown between trials. Each eye was tested separately. This experiment utilized a 2-alternative temporal forced-choice contrast matching paradigm. For each trial, the eye being tested viewed one temporally sequenced vertical sinusoidal grating stimulus. The non-tested eye viewed a masking grating in both epochs. The gratings are referred to as the reference and mask in the adjacent figure, but they are identical. The reference and mask grating was shown at $2 \mathrm{cpd}$ and one of 3 contrast levels, to create three conditions of interest. The test grating has the same spatial frequency as the reference and mask. If we take the "Test OS" conditions as an example, the contrast values of the reference and the mask grating are set to either $0.1 \log$ unit below, $0.5 \log$ unit above or $1.0 \log$ unit above OD's monocular threshold. The test grating was shown to OS in one of the two epochs, randomly chosen and a staircase procedure will find the test grating contrast that was detectable in the presence of the reference and the mask. For each trial the subject made a perceptual decision as to which grating stimulus possesses the most contrast ("which has more contrast"). A starting contrast of $40 \%$ was used. The perpetration time, show time and accept time were 500, 200 and $1800 \mathrm{msec}$, respectively. The result of this procedure is a set of physical contrast values that equate the test + mask with the reference stimulus for three levels of contrast. This entire test was then repeated for the "Test OD" condition which reverses the above description of the two eyes.

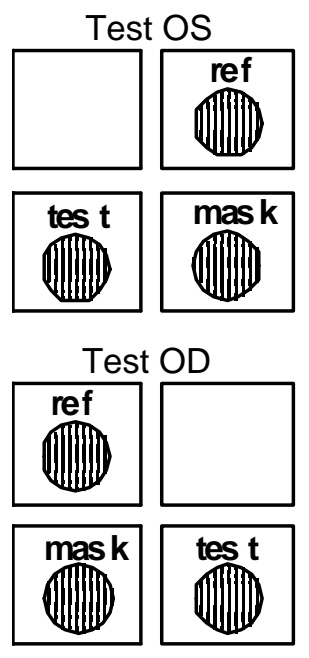

Figure 5: Binocular integration stimulus 


\section{Randot stereotest}

The Randot test is one of the commonly used clinical tests of stereopsis. This test was performed as a part of the clinical examination at West Virginia University hospitals. The subjects were asked to wear a pair of glasses with appropriately polarized lenses, and to distinguish between "raised circles" and distracter circles with no stereo offset. Nine trials of increasing difficulty are included. The scoring system ranged from 0 to 9 where 0 is minimum and 9 is maximum.

\section{Statistical analysis}

Analyses of the data were performed using the JMP software package (SAS Institute Inc, NC, USA). To test for significant impairments for both amblyopic subtypes analysis of variance (ANOVA) was performed. In monocular tests for acuities (Snellen, grating and Vernier) two factors were used: diagnosis (control, strabismic, anisometropic) and eye tested (amblyopic, fellow). For contrast sensitivity, spatial frequency (1, 2 or 4 cpd) was used in addition to the above two factors. Statistical significance was defined as $\mathrm{p}<0.05$. Pearson correlation was performed to find correlations between different monocular acuities, different binocular acuities and in between monocular and binocular acuities. R-square value of more than 0.5 was considered significant.

ANOVA for binocular motion integration involved two factors: diagnosis (control, strabismic, anisometropic) and spatial frequencies $(0.312,0.625,1.25,2.5$ and $5.0 \mathrm{cpd}$ ). For Randot circle stereopsis, diagnosis was the only factor. To understand the effects of different masks in case of binocular contrast integration, individual analysis of different conditions was more useful. Hence we calculated the probabilities based on one tailed student's t-test after comparing specific subcategories of amblyopes with normal subjects.

We also subdivided our subjects as "binocular" and "non-binocular" based on our binocular criteria mentioned in the results section. Some ANOVAs were then repeated using binocularity rather than etiology as the diagnosis factor. Pearson's correlation was done for different monocular acuities using these subgroups classified on the basis of 
binocularity. For all the ANOVA described above we also did two-way or three way ANOVA wherever applicable.

\section{RESULTS}

\section{Monocular tests}

* Figures are collected at the end of this section

\section{Snellen acuity}

ANOVA for anisometropes versus control groups showed a main effect of diagnosis $(F=6.4 ; p=0.02)$ and a main effect of eye tested $(F=5.2 ; p=0.03)$ (Table 4, Figure 6). In addition, the interaction between the two factors approached significance $(F=4.0 ; p=0.056)$. The comparison of strabismics versus control groups approached significance for diagnosis $(F=3.7 ; p=0.07)$ and eye tested $(F=3.6 ; p=0.07)$. Inspection of the data indicates that high variability between strabismic subjects contributed to a lack of a significance effect. Table 4 summarizes the weak and fellow eye's Minimum Angle of Resolution (MAR).

\section{Grating acuity}

Table 4 and Figure 7 demonstrate the weak and fellow eye's grating acuities in minutes of visual angle. The ANOVA for anisometropes versus control groups, showed a main effect of diagnosis $(F=5.0 ; p=0.04)$, a main effect of eye tested $(F=8.6 ; p=$ $0.007)$ and interaction between diagnosis and eye tested $(F=8.8 ; p=0.007)$. When strabismic subjects were compared with control group, the effect of diagnosis demonstrated a significant main effect $(F=4.1 ; p=0.05)$. However; similar to the results for Snellen acuity, no significant effect of eye condition or interaction between the factors was observed.

\section{Vernier acuity}


For the Vernier acuity tests, anisometropes when compared to control subjects, showed a significant effect of diagnosis $(F=4.1 ; p=0.05)$ on ANOVA (Table 4, Figure 8). No effect of eye condition or its interaction with diagnosis was observed. Strabismics on the other hand showed both the effect of diagnosis $(F=5.0 ; p=0.04)$ and eye condition $(F=4.8 ; p=0.04)$. The interaction between diagnosis and eye condition approached statistical significance $(\mathrm{F}=3.8 ; p=0.06)$.

\section{Monocular contrast sensitivity functions}

The primary aim of the contrast sensitivity functions is to replicate the standard contrast sensitivity curves. The standard contrast sensitivity functions show their maximum values at middle spatial frequencies of 2-4 cpd in normal subjects. The normal subjects showed peak response at 2 cpd as expected, while the strabismics and anisometropes performed best at $1 \mathrm{cpd}$ (Figures 9, 10). When comparing anisometropes with control subjects using ANOVA, significant main effects of all the three factors i.e. spatial frequency $(F=6.0 ; p=0.004)$, diagnosis $(F=16.6 ; p=0.0001)$ and eye condition $(\mathrm{F}=9.7 ; \mathrm{p}=0.003)$ were observed. Also, two-way interactions between diagnosis and eye condition $(\mathrm{F}=8.3 ; \mathrm{p}=0.005)$ and diagnosis and spatial frequencies $(\mathrm{F}=3.8 ; \mathrm{p}=$ 0.03) were also significant (Table 5). In contrast, when we compared the strabismic group with controls, we did not obtain any significant effects except for an overall main effect of eye condition ( $F=4.0 ; p=0.05)$, with no an interaction with diagnosis or spatial frequency. Again variability between subjects was high for the strabismic eyes.

Table 4:: Mean Snellen, grating, and Vernier acuity of subjects

\begin{tabular}{|c|c|c|c|c|}
\hline Categories & Eye condition & $\begin{array}{c}\text { Snellen acuity } \\
\text { (MAR) }\end{array}$ & $\begin{array}{c}\text { Grating Acuity } \\
\text { (Arc-Minutes) }\end{array}$ & $\begin{array}{c}\text { Vernier Acuity } \\
\text { (Arc-Minutes) }\end{array}$ \\
\hline \multirow{2}{*}{$\begin{array}{c}\text { Normals } \\
(\mathrm{n}=7)\end{array}$} & Weak eye & 1.01 & 0.79 & 0.11 \\
\cline { 2 - 5 } & Fellow eye & 0.89 & 0.80 & 0.09 \\
\hline Strabismic & Weak eye & 3.07 & 1.09 & 0.23 \\
\hline
\end{tabular}




\begin{tabular}{|c|c|c|c|c|}
\hline$(\mathrm{n}=6)$ & Fellow eye & 0.98 & 0.90 & 0.10 \\
\hline $\begin{array}{c}\text { Anisometropic } \\
(\mathrm{n}=7)\end{array}$ & Weak eye & 3.04 & 1.21 & 0.34 \\
\cline { 2 - 5 } & Fellow eye & 1.12 & 0.73 & 0.19 \\
\hline
\end{tabular}

Table 5: : Mean contrast thresholds (\%)

\begin{tabular}{|c|c|c|c|c|c|c|}
\hline & \multicolumn{3}{|c|}{ Weak eye } & \multicolumn{3}{c|}{ Fellow Eye } \\
\hline Categories & $\mathbf{1 ~ c p d}$ & $\mathbf{2}$ cpd & 4cpd & $\mathbf{1}$ cpd & $\mathbf{2}$ cpd & $\mathbf{4}$ cpd \\
\hline Normals & 1.81 & 1.59 & 2.82 & 1.72 & 1.51 & 2.24 \\
\hline Strabismic & 2.57 & 4.11 & 11.75 & 1.23 & 1.87 & 2.58 \\
\hline Anisometropic & 3.20 & 8.93 & 16.60 & 1.95 & 2.35 & 4.89 \\
\hline
\end{tabular}

Overall, when comparing the four monocular tests, it is apparent that Snellen acuity, grating acuity, and CSF were similar in their ability to demonstrate significant impairments specific for anisometropic eyes, but generally not in strabismic eyes. In contrast, the results for Vernier acuity produced impairments specific to the strabismics eyes. To more formally test the relationship between tests Pearson Product correlation was performed.

\section{Correlation among monocular tests}

The relationship between grating and Snellen acuity for the weak eyes of amblyopes and both eyes in normals was described by a straight line with positive slope which was statistically significant $\left(R^{2}=0.51 ; p=<0.0001\right)$ (Figure 11). Similarly, significant correlation was found between Snellen acuity and Vernier acuity $\left(R^{2}=0.69 ; p\right.$ $=<0.0001)$ (Figure 12). However, when this correlation between Snellen and Vernier acuity was done separately for two diagnosis, the anisometropic amblyopes $\left(R^{2}=0.91 ; p\right.$ $=0.0007)$ showed a much stronger correlation as compared to strabismics amblyopes $\left(R^{2}\right.$ $=0.51 ; p=0.10$ ) (Figure 13). No significant Pearson's correlation was present when grating acuity was compared with Vernier acuity. 


\section{Comparison of the three monocular acuities}

Figure 11 shows the relationship between the grating and Snellen acuity. In addition to bivariate fit line (red), the 1:1 slope line is shown in black. Points falling below the line signify better grating acuity as compared to Snellen acuity. The normal subjects mostly lie at or slightly away from the diagonal line, whereas the amblyopic eyes are far below than normal. The anisometropes showed greater departure from the 1:1 line than strabismics. In the cases of anisometropic observers JL and AG, with Snellen's acuity values of 20/63 each, the grating acuity greatly underestimates the loss in Snellen acuity. Our data are very close to that mentioned in pervious studies (Levi and Klein, 1982a) except in our case anisometropes were more impaired on Snellen than strabismics.

The ratio of grating and Vernier acuity is sometimes referred to as the resolution ratio (Levi and Carkeet, 1993). The normal subjects in our study population had a resolution ratio of 12.3:1.0 which signifies that Vernier resolution is approximately 12.3 times better than the grating acuity. Amblyopic eyes demonstrated lesser resolution ratios on average (anisometropic weak eye 6.1:1; strabismic weak eye 5.8:1). The most severe amblyopes KT in our subset performed almost 1:1 ratio. 


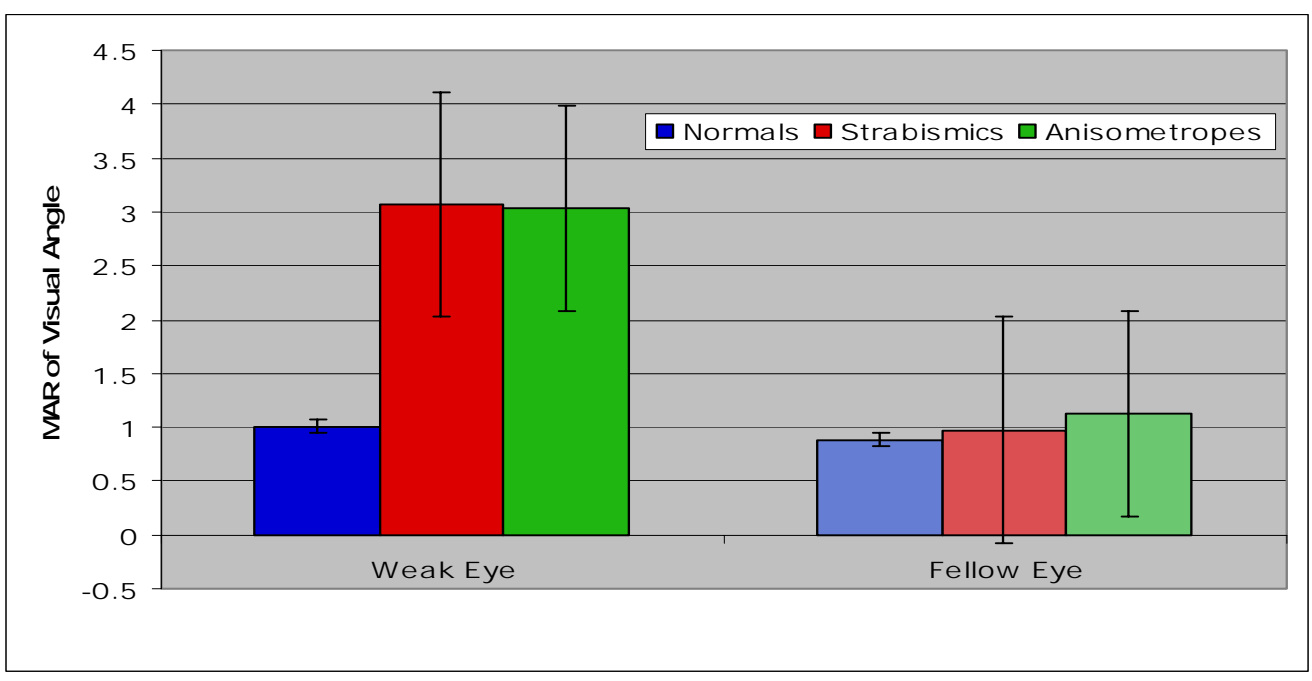

Figure 6: Grating acuity for three categories of subjects (Minutes of Visual angle); error bars indicate +/- SEM

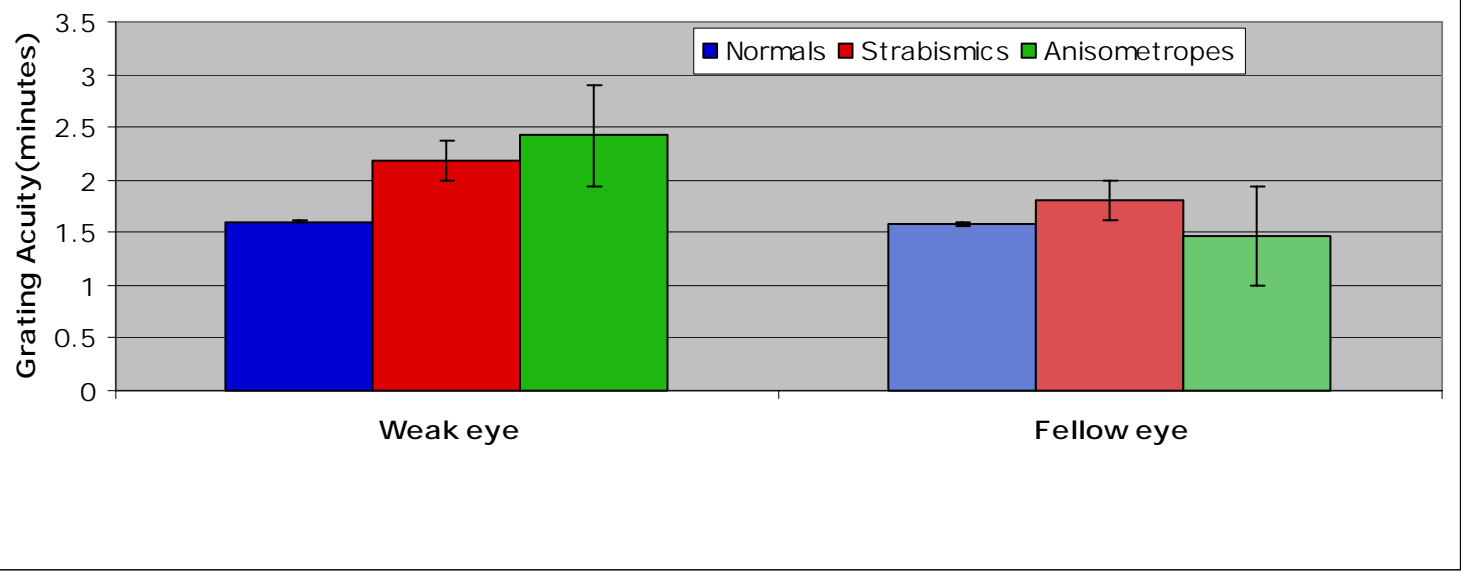

Figure 7: Grating acuity for three subject categories of subjects (minutes of visual angle), error bars indicate +/- SEM 


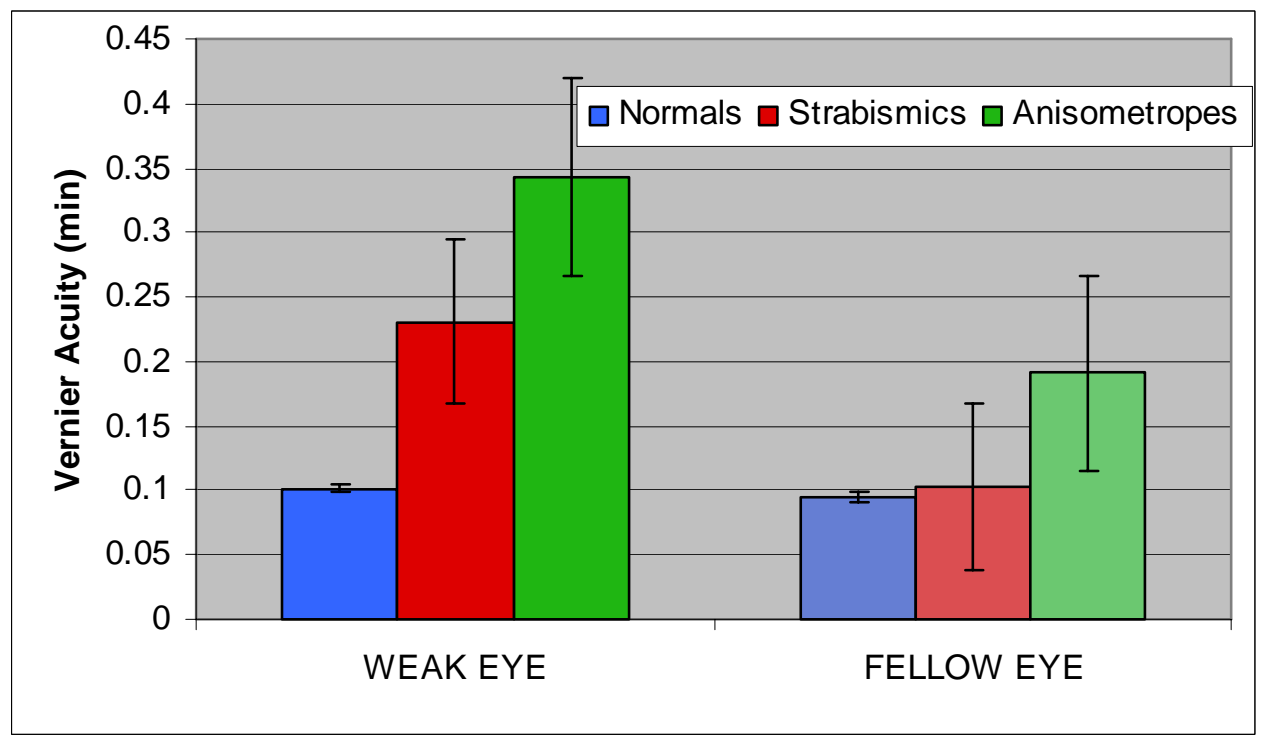

Figure 8: Vernier acuity of three categories of subjects measured in minutes, error bars indicate +/SEM

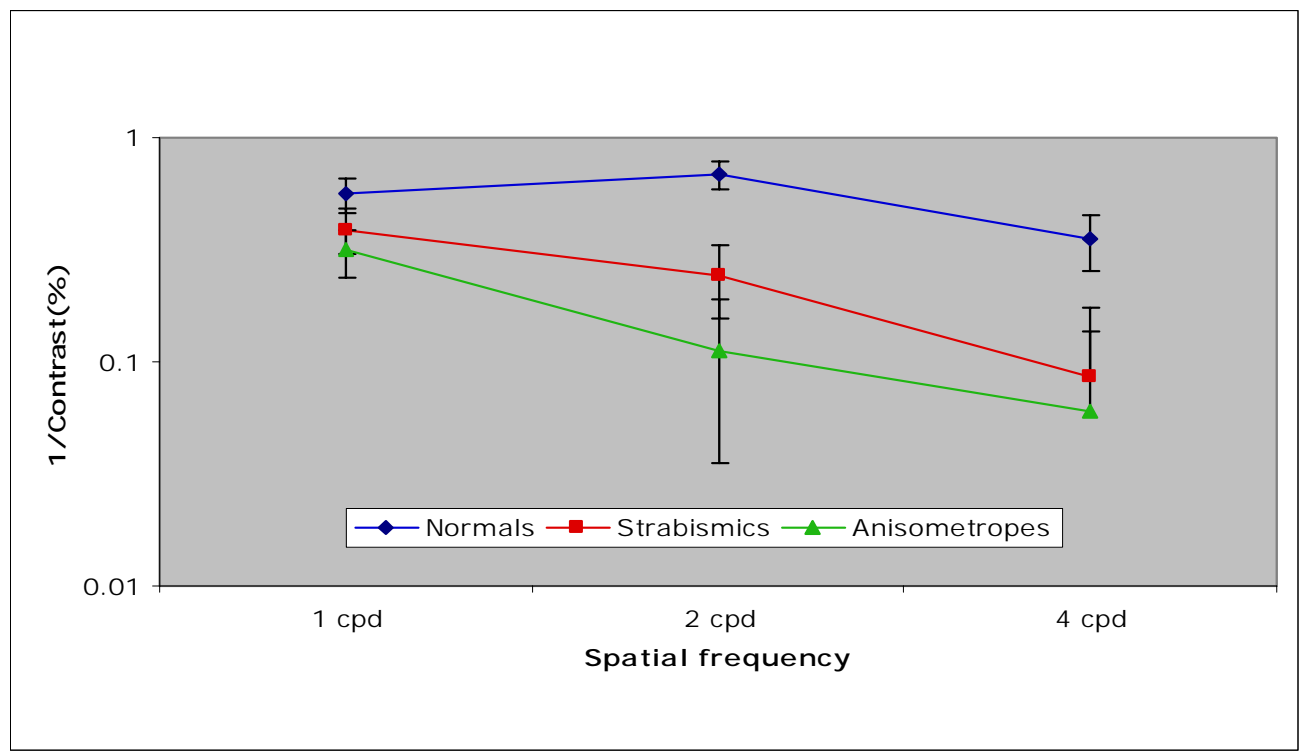

Figure 9: Contrast sensitivity function for the weak eye for the three subject groups, error bars indicate +/- SEM 


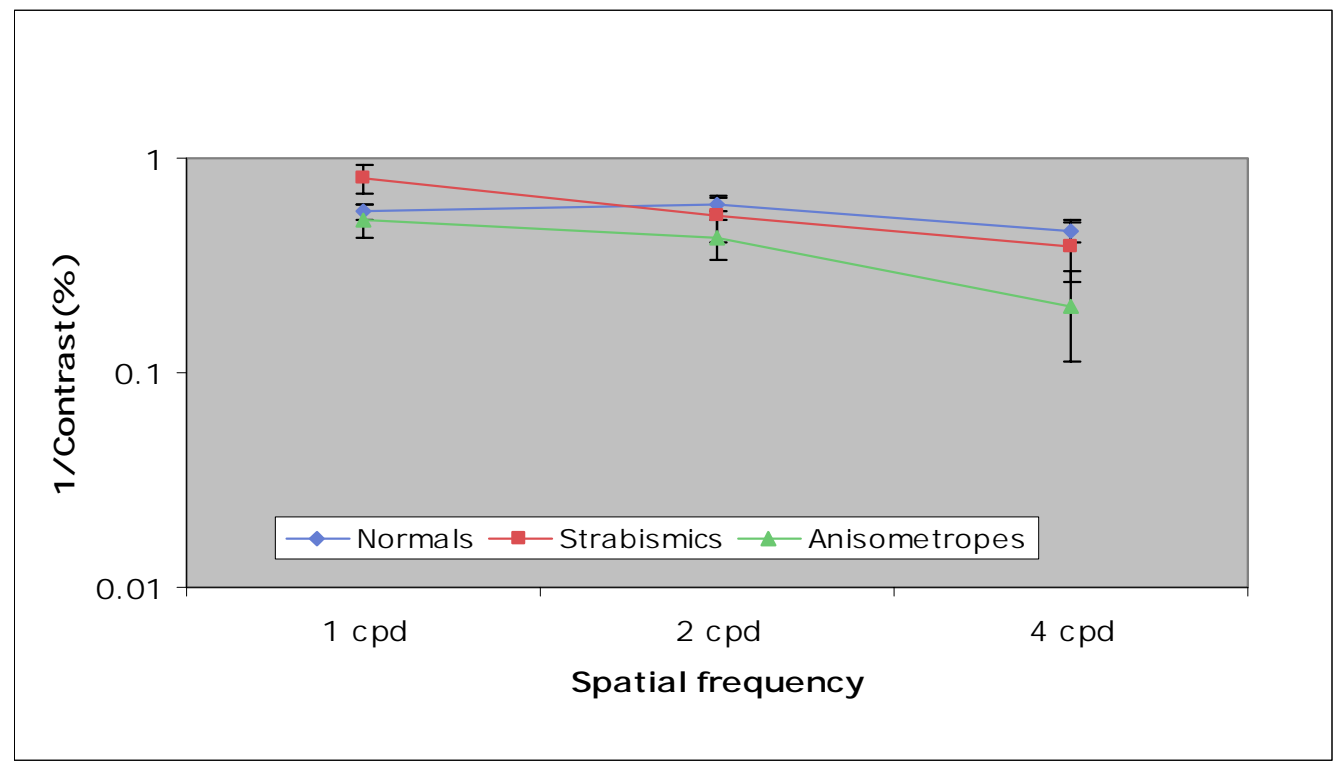

Figure 10: Contrast sensitivity function for the fellow eye in three subgroups of subjects, Error bars indicate $+/$ - SEM

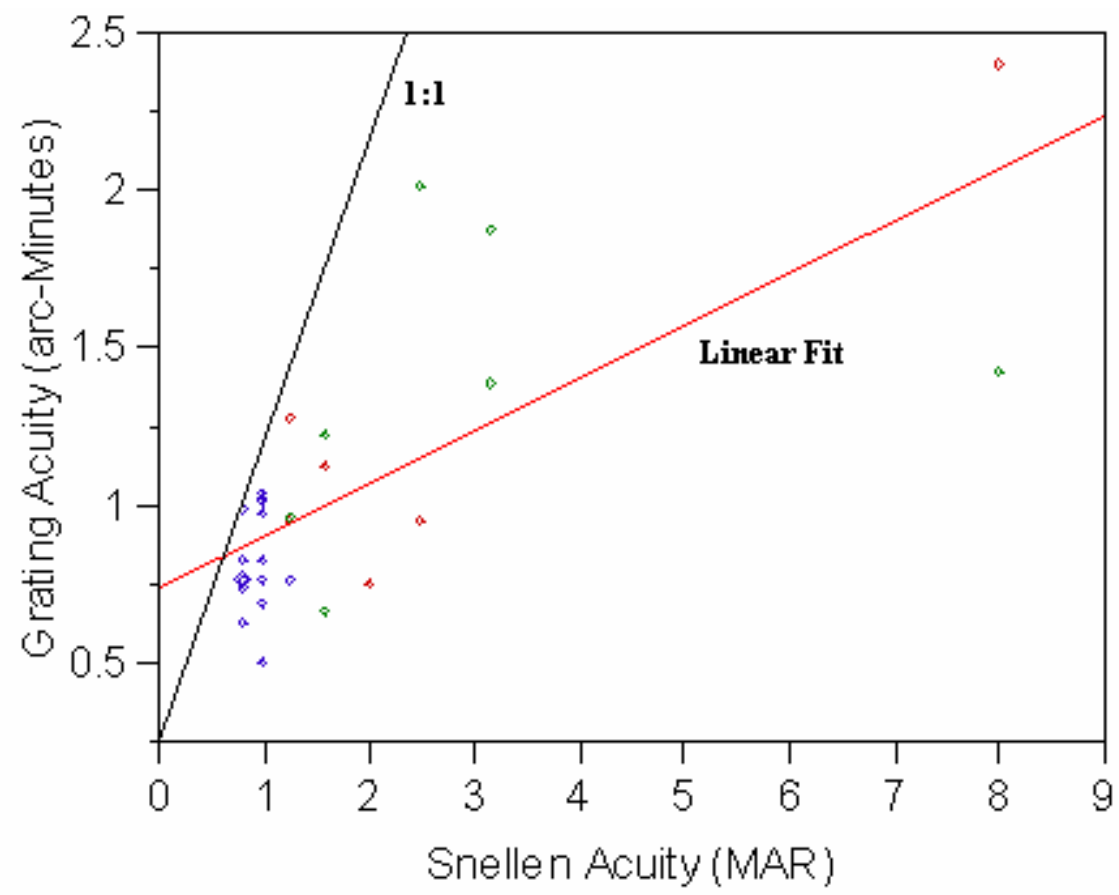

Figure 11: Bivariate fit of Grating Acuity (arc-Minutes) by Snellen Acuity (MAR), (blue dots= control subjects, red dots $=$ strabismics, green dots $=$ anisometropics) 


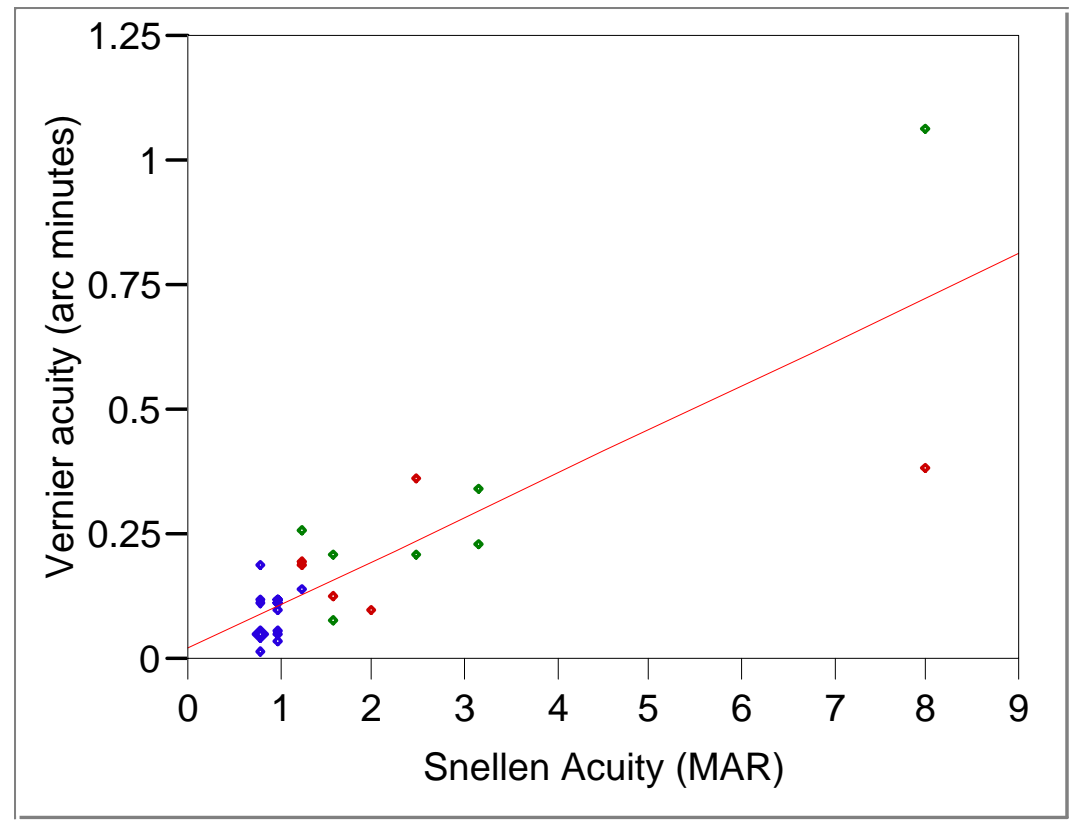

Figure 12: Bivariate fit of Vernier Acuity (arc-Minutes) by Snellen Acuity (MAR) (blue dots= control subjects, red dots $=$ strabismics, green $\operatorname{dots}=$ anisometropics)

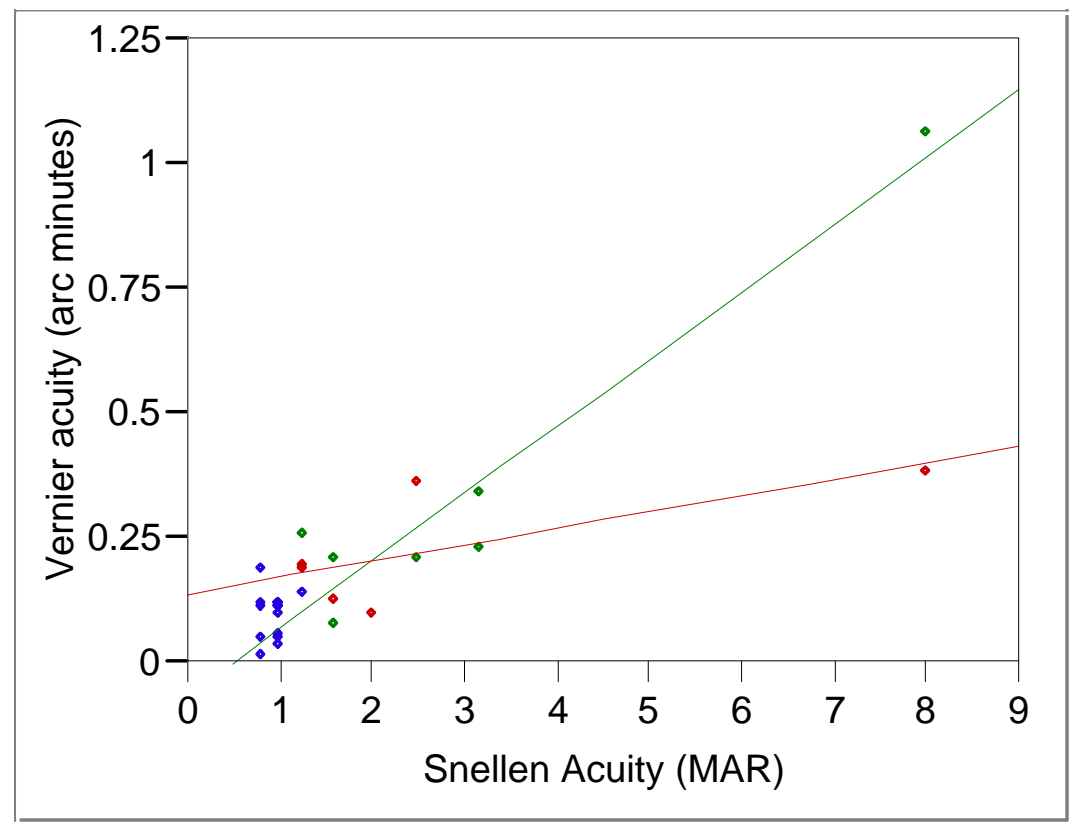

Figure 13: Bivariate fit of Vernier Acuity (arc-Minutes) by Snellen Acuity (MAR) based on clinical classification. $($ Red $=$ anisometropic amblyopes, green $=$ strabismic amblyopes $)$ 


\section{Binocular tests}

(*Figures are collected at the end of this section)

\section{Randot stereopsis test}

This widely used clinical test which is specific for stereoacuity also demonstrated significant deficits in our subjects (Figure 17). ANOVA for anisometropes when compared to normal subjects was highly significant for the effect of diagnosis $(F=$ 147.5; $p<0.0001)$. Similarly when strabismics were compared to normals they showed also a very significant difference $(F=207.3 ; p<0.0001)$.

\section{Binocular motion integration}

An illusion of motion in one direction was perceived when two stimuli that are spatially and temporally out of phase by 90 degrees were shown to the two eyes. The subject's ability to integrate the stimuli binocularly determines the correct or incorrect performance in the test. As mentioned earlier, we presented our subjects with five spatial frequencies (Figure 14).

The normal subjects showed an interesting spatial frequency dependency pattern. Their performance was best at low spatial frequencies, however with increase in the spatial frequencies there was a significant decrease in performance, and at around $5 \mathrm{cpd}$ their performance was close to chance. There was a significant difference in performance among normal subjects when the higher spatial frequencies were compared with the lowest $0.312 \mathrm{cpd}$ performance. The $\mathrm{p}$ values for matched paired t-tests for 1.25, 2.5 and $5.0 \mathrm{cpd}$ were $\mathrm{p}=0.02,0.01$ and 0.0001 respectively.

On performing ANOVA for comparison of anisometropic and normal groups significant effect of diagnosis $(F=10.1 ; p<0.0001)$ and spatial frequency $(F=36.6$; $p<$

0.0001) was present. Interaction between spatial frequencies and diagnosis was not significant. Comparison of strabismics with normal subjects demonstrated significant effects of diagnosis $(F=70.1 ; p<0.0001)$, spatial frequencies $(F=6.0 ; p<0.001)$ as 
well as an interaction between diagnosis and spatial frequencies $(F=5.5 ; p<0.001)$. Interestingly, like control subjects, anisometropes performed well on the low spatial frequency, whereas at higher spatial frequencies their performance was close to chance. Strabismics performed worse than expected at all the spatial frequencies.

\section{Binocular contrast integration}

For the binocular integration tests we use the terminology "summation" when the binocular performance was better than the monocular performance, while "inhibition" signified that the binocular performance was worse than monocular.

\section{Binocular contrast integration in the fellow eye}

Figure 16 shows the effect of masks in the amblyopic or non-dominant eye on the performance of the fellow eye or the dominant eye of control subjects. One tailed student's t-tests were performed to compare each amblyopic subtype with control subject (Table 8). None of these comparisons reached statistical significance, but there were quite some interesting trends. On average, normal subjects showed the effect of summation, i.e., performance was improved in the dominant eye when a sub-threshold mask was presented to the non-dominant eye (compared to the standard, no mask condition, 'Thresh'). Interestingly, the effect of summation was also present with a $0.5 \log$ unit supra-threshold mask. However, at 1.0 log unit supra-threshold mask inhibition was present. In other words, much more contrast is required to detect the test grating than when no mask is present. For anisometropic and strabismic subjects, inhibition was present with all the masks, suggesting that any stimulation of the amblyopic eye is detrimental to fellow eye performance (compared to the standard threshold). Interestingly, with a $1.0 \log$ unit supra-threshold mask both the amblyopic groups showed less inhibition than normal subjects. This indicated that amblyopic eyes have an abnormally reduced ability to inhibit the fellow eyes. 


\section{Binocular contrast integration in amblyopic eye}

In comparison with Figure 16, Figure 17 demonstrates the effect of masks in the fellow eye of amblyopes, or preferred eye of controls, on the performance of the amblyopic or non-preferred eye. Please note that in Figure 2 the $y$-axis is expanded as compared to Figure 1 for clarity, but the masking effects are much larger in this case. At sub-threshold masks all the three subject subgroups demonstrated inhibition. Stimulation of the dominant eye always reduced the performance of the non-dominant eye. In fact, the anisometropes demonstrated a very significant inhibition with the sub-threshold mask (Table 8), much higher than normal subjects and strabismics. Furthermore, with $1.0 \log$ unit supra-threshold masks, both the amblyopic groups showed significantly more inhibition than normal subjects, in contrast with the previous results. This indicates that fellow eyes have an abnormally high ability to inhibit amblyopic eyes.

Table 6: Binocular motion integration (average percentage correct trials)

\begin{tabular}{|c|c|c|c|c|c|}
\hline Categories & $\mathbf{0 . 3 1 2}$ cpd & $\mathbf{0 . 6 2 5}$ cpd & $\mathbf{1 . 2 5}$ cpd & $\mathbf{2 . 5}$ cpd & $\mathbf{5 . 0}$ cpd \\
\hline Normal & 96.43 & 94.29 & 79.29 & 80.71 & 57.14 \\
\hline Strabismus & 63.33 & 43.33 & 48.33 & 55.83 & 53.33 \\
\hline Anisometropia & 78.57 & 61.43 & 51.43 & 56.43 & 49.29 \\
\hline
\end{tabular}

Table 7: Binocular contrast integration (\%) and randot test

\begin{tabular}{|c|c|c|c|c|c|c|}
\hline \multirow{2}{*}{ Diagnosis } & \multirow{2}{*}{$\begin{array}{c}\text { Randot } \\
\text { Test }\end{array}$} & \multirow{2}{*}{ Eye } & \multirow{2}{*}{$\begin{array}{c}\text { Monocular } \\
\text { Threshold }\end{array}$} & & \multicolumn{3}{|c|}{$\begin{array}{c}\text { Mask in non tested eye } \\
\text { threshold }\end{array}$} & $\begin{array}{c}\text { 0.5 Supra } \\
\text { threshold }\end{array}$ & $\begin{array}{c}\text { 1.0 Supra } \\
\text { threshold }\end{array}$ \\
\hline \multirow{2}{*}{ Control } & \multirow{2}{*}{40} & Dominant & 1.82 & 1.29 & 1.68 & 10.31 \\
\cline { 3 - 7 } & & Non domin & 1.06 & 1.89 & 5.83 & 17.01 \\
\hline \multirow{2}{*}{ Strabismics } & \multirow{2}{*}{866.67} & Fellow & 1.65 & 1.79 & 3.47 & 6.30 \\
\cline { 3 - 7 } & & Weak & 4.11 & 6.64 & 16.10 & 40.99 \\
\hline \multirow{2}{*}{ Anisometropes } & \multirow{2}{*}{757.14} & Fellow & 2.35 & 2.90 & 4.72 & 6.10 \\
\cline { 3 - 7 } & & Weak & 8.92 & 29.47 & 21.50 & 51.58 \\
\hline
\end{tabular}

\footnotetext{
${ }^{\#}$ Randot stereoscopic test is expressed in terms of angle of stereopsis at 16 inches.
} 
Table 8: $T$ value and $p$ values on comparing amblyopic subgroups with corresponding normal eyes (t value; $p$ value)

\begin{tabular}{|c|c|c|c|c|}
\hline \multirow{2}{*}{ Diagnosis } & \multicolumn{2}{|c|}{ Weak Eye } & \multicolumn{2}{c|}{ Fellow eye } \\
\cline { 2 - 5 } & Anisometropes & Strabismics & Anisometropes & Strabismics \\
\hline $0.1 \log$ Sub & $2.51 ; 0.02$ & $2.29 ; 0.04$ & $1.66 ; 0.122$ & $0.71 ; 0.49$ \\
\hline $0.5 \log$ Supra & $2.26 ; 0.04$ & $1.59 ; 0.13$ & $1.34 ; 0.24$ & $1.20 ; 0.25$ \\
\hline $1.0 \log$ Supra & $3.00 ; 0.01$ & $1.86 ; 0.09$ & $1.12 ; 0.28$ & $0.4 ; 0.69$ \\
\hline
\end{tabular}

Re-classification of amblyopic subjects on the basis of binocularity:

Next, we re-classified our subjects based on residual binocularity rather than clinical diagnosis. We used two binocular tests to classify our subjects according to a pass-fail criterion, where pass means being able to perform the test at any level. For motion integration we used the pass cut off value of $>70 \%$ correct for $0.312 \mathrm{cpd}$. (Shadlen and Carney, 1986b). For the randot sterotest we determined whether the score was greater than or equal to zero. The subjects who passed both the tests are designated as binocular while those who did not pass both were classified as non-binocular. Of all our amblyopes $33.3 \%$ of strabismics and $57 \%$ of anisometropes qualified for the binocular category.

We performed an ANOVA to compare the normal subjects with amblyopic subjects with the new classification. The factors used were eye (fellow (dominant), weak (non dominant)), binocularity (binocular, non-binocular, normal). The tests analyzed were Snellen acuity, Grating acuity and Vernier acuity. In this way we examined the relationship between binocular vision and monocular acuity.

To determine if the amblyopic binoculars, whom we defined according to our criteria, are different from the normal subjects, ANOVA was performed. The effect of diagnosis was not significant for Vernier acuity. This means that our binocular group was not significantly different than normal subjects in terms of Vernier acuity. However, for Snellen and grating acuities, the binocular group performed significantly worse than normals $(F=18.85 ; p=0.0002 ; F=4.2 ; p=0.05$, respectively $)$. The effect of eye tested 
was also significant for all three acuities as well as the interaction between the two factors. On the other hand, ANOVA for non-binoculars when compared to normals verified that effect of diagnosis was evident for all three acuities. The various $\mathrm{F}$ ratios and $\mathrm{p}$ values are summarized in Table 9. Thus the non-binocular group is distinguished from the binocular group by showing abnormal Vernier acuity, further reinforcing the idea that binocular functions can predict a loss of "hyperacuity".

Table 9: ANOVA results for the three acuities. For factors the $F$ ratio and $p$ values are shown separated by semi colon (;). The non-significant values are shown in black.

\begin{tabular}{|c|c|c|c|c|}
\hline \multirow{2}{*}{ Acuity } & Binocularity & Diagnosis & Eye condition & $\begin{array}{c}\text { Interaction b/w } \\
\text { two factors }\end{array}$ \\
\hline \multirow{2}{*}{ Snellen } & Binocular & $18.9 ; 0.0002$ & $16.5 ; 0.0004$ & $10.7 ; 0.0032$ \\
\cline { 2 - 5 } & Non-Binocular & $5.6 ; 0.03$ & $4.9 ; 0.04$ & $4.1 ; 0.4$ \\
\hline \multirow{2}{*}{ Grating } & Binocular & $4.2 ; 0.05$ & $5.1 ; 0.03$ & $5.3 ; 0.03$ \\
\cline { 2 - 5 } & Non-Binocular & $4.6 ; 0.04$ & $3.1 ; 0.09$ & $3.2 ; 0.09$ \\
\hline \multirow{2}{*}{ Vernier } & Binocular & $3.9 ; 0.06$ & $5.7 ; 0.03$ & $4.3 ; 0.05$ \\
\cline { 2 - 5 } & Non-binocular & $5.9 ; 0.02$ & $1.2 ; 0.29$ & $1.0 ; 0.32$ \\
\hline
\end{tabular}

\section{Correlation between acuities using binocular and non-binocular sub groups}

On comparing grating acuity with Snellen acuity both the subgroups showed significant correlations (binocular: $R^{2}=0.64 ; p=0.0018$ and non-binocular $R^{2}=0.71$; $p=0.002$ ) (Figure 18). The relationship between Vernier and Snellen acuity for amblyopes using Pearson's correlation was described by a straight line with positive slope (Figure 19). It was statistically significant for binocular subjects $\left(R^{2}=0.56 ; p=\right.$ 0.005), but not significant for non-binocular group. Finally, the correlation of grating acuity with Vernier acuity yielded significant correlation for binocular subjects $\left(R^{2}=\right.$ 0.52; $p=0.0085$ ) and not for non-binocular subjects (Figure 20). The lack of correlation for the non-binocular group once again indicates that severity of deficit in non-binoculars cannot be predicted by loss in grating acuity. 


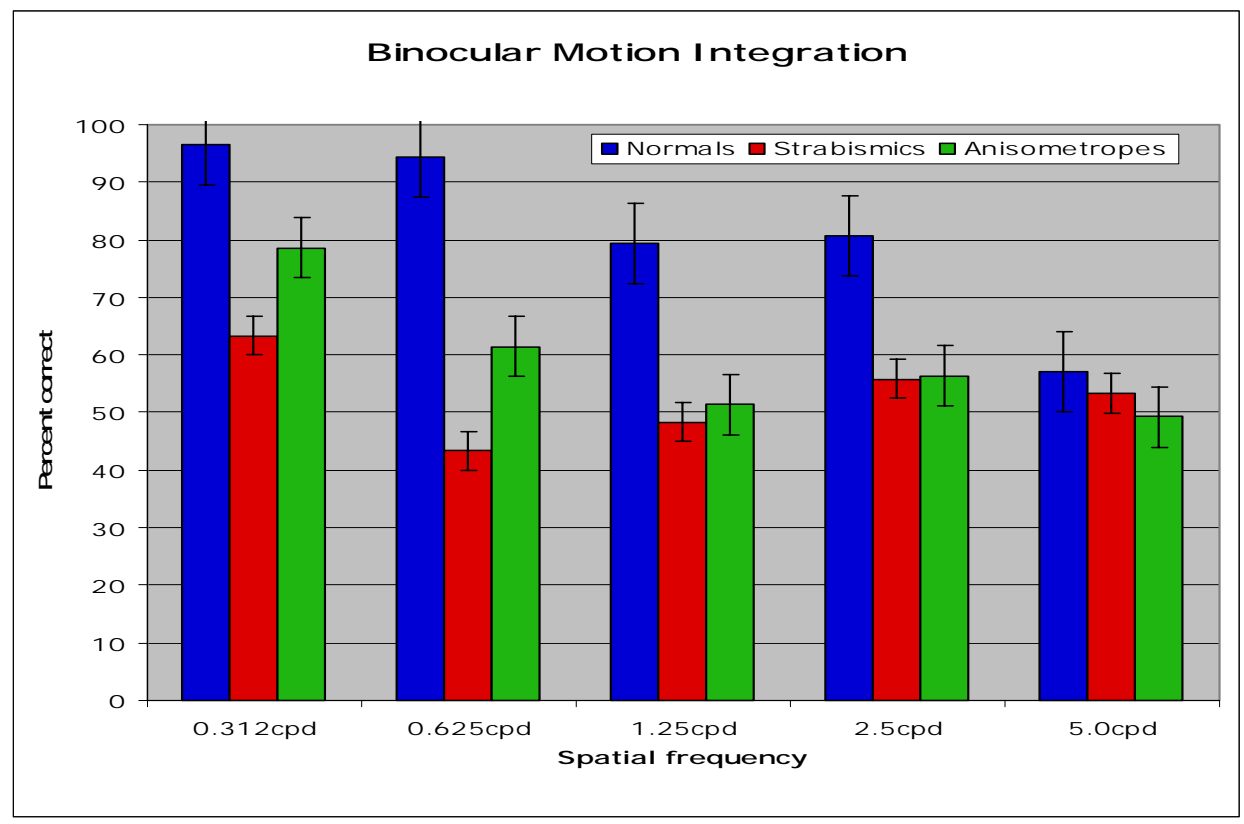

Figure 14: Binocular contrast integration (average correct) across three groups of subjects, error bar indicate +/- SEM

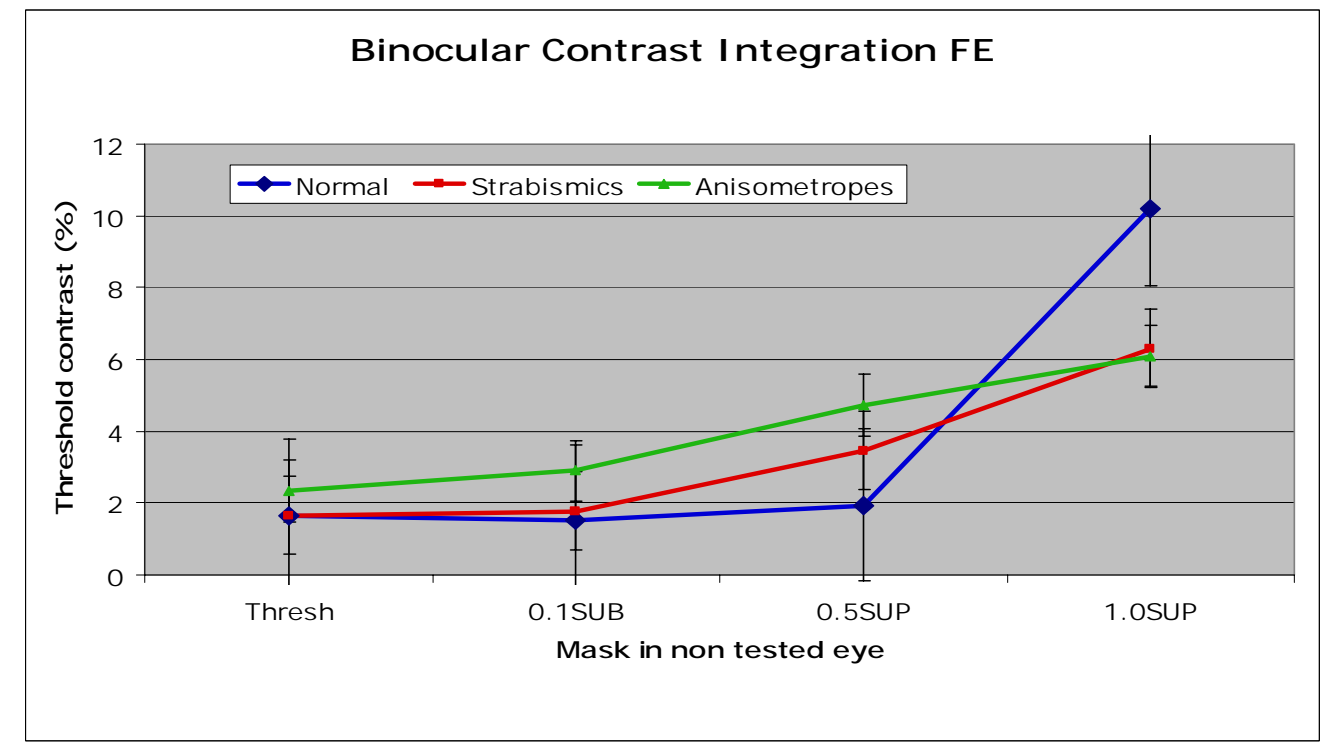

Figure 15: Binocular contrast integration for the fellow eye across three groups of subjects, error bar indicate +/- SEM 


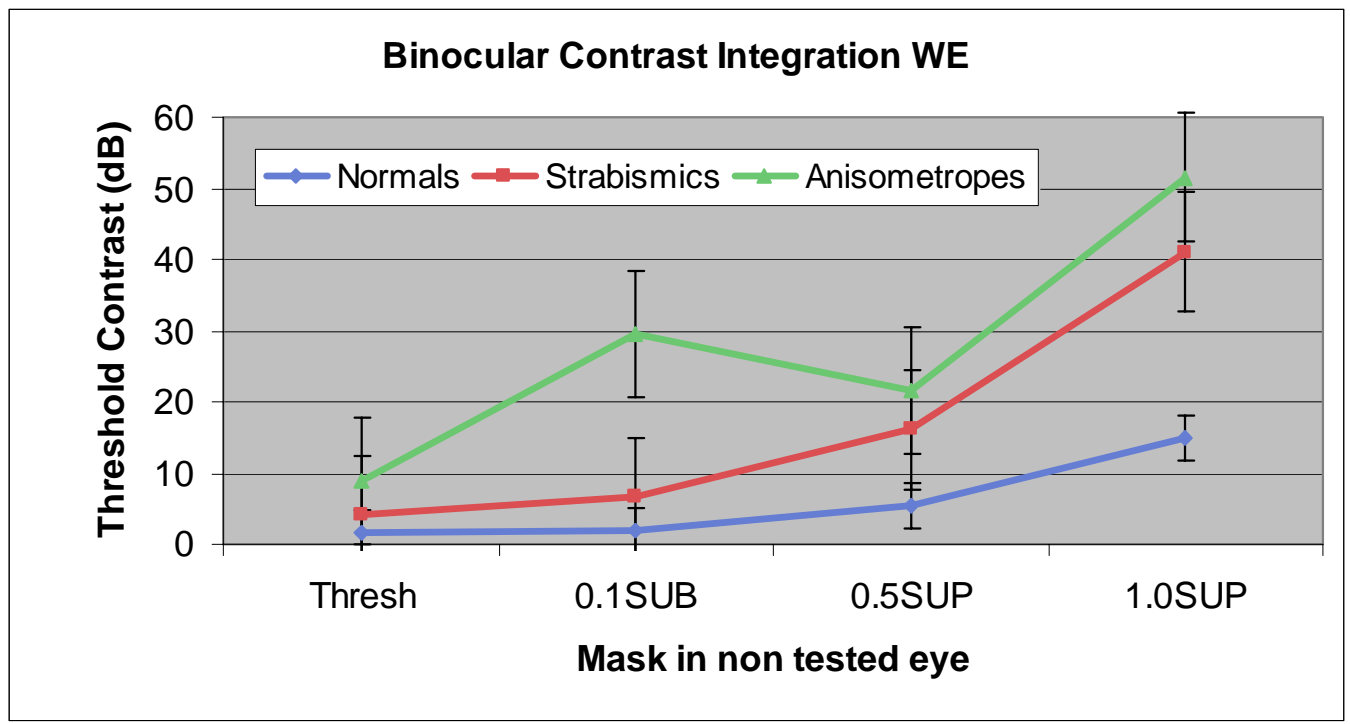

Figure 16: Binocular contrast integration for the fellow eye across three groups of subjects, error bar indicate +/- SEM

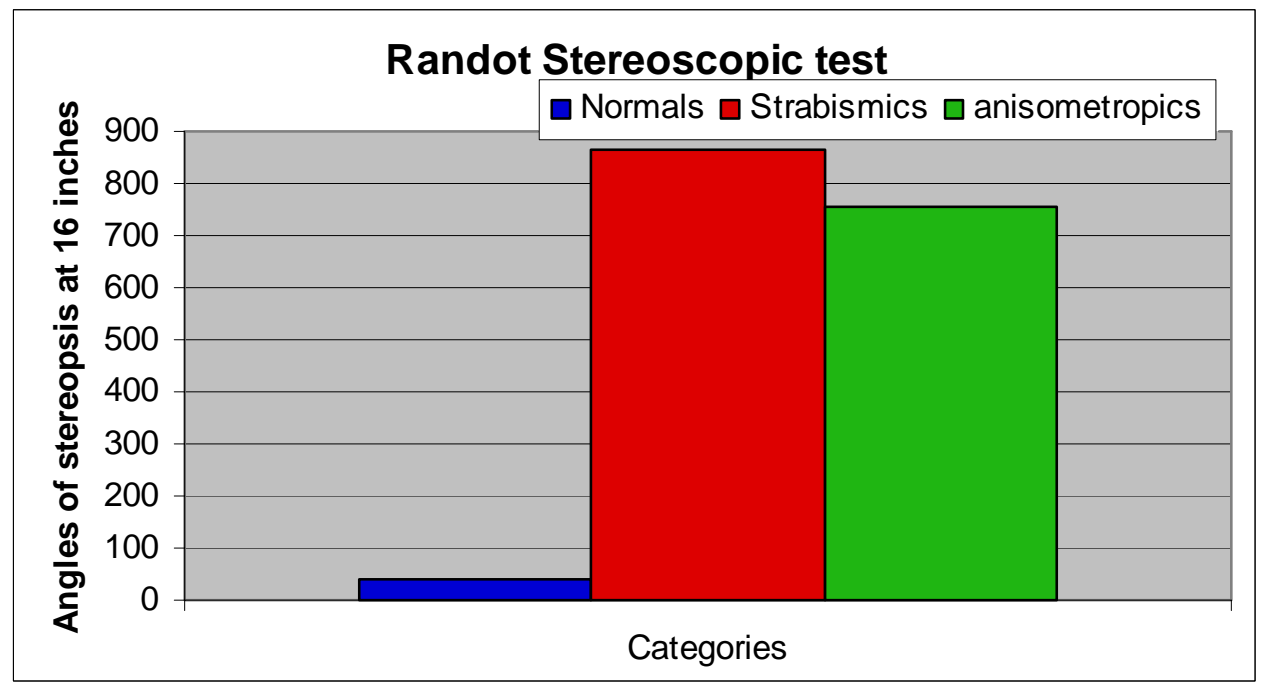

Figure 17: Randot stereoscopic test average across three groups of subjects., error bar indicate +/SEM, error bars very small and hence merge with the bars. 


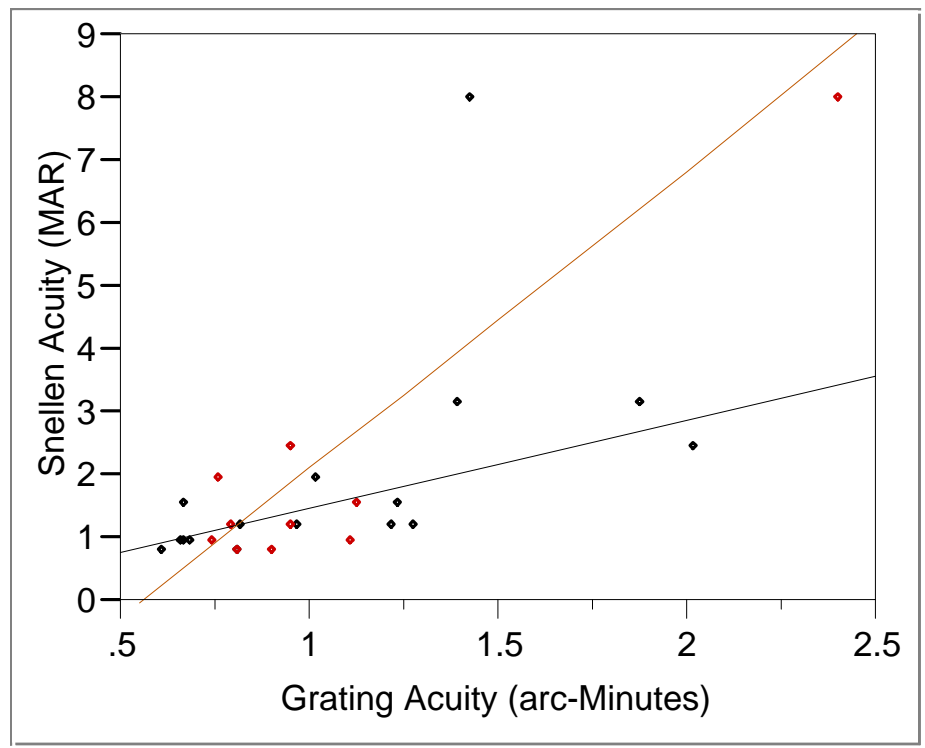

Figure 18: Bivariate Fit of Snellen Acuity (MAR) By grating Acuity (Arc Minutes)

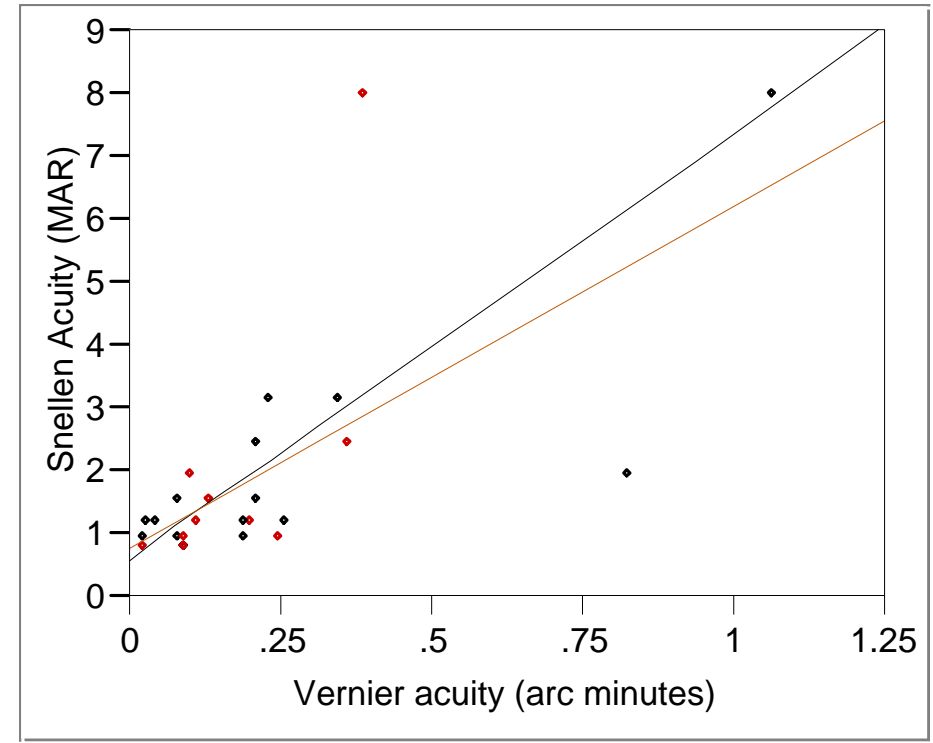

Figure 19: Bivariate Fit of Snellen Acuity (MAR) by Vernier Acuity (Arc Min) 


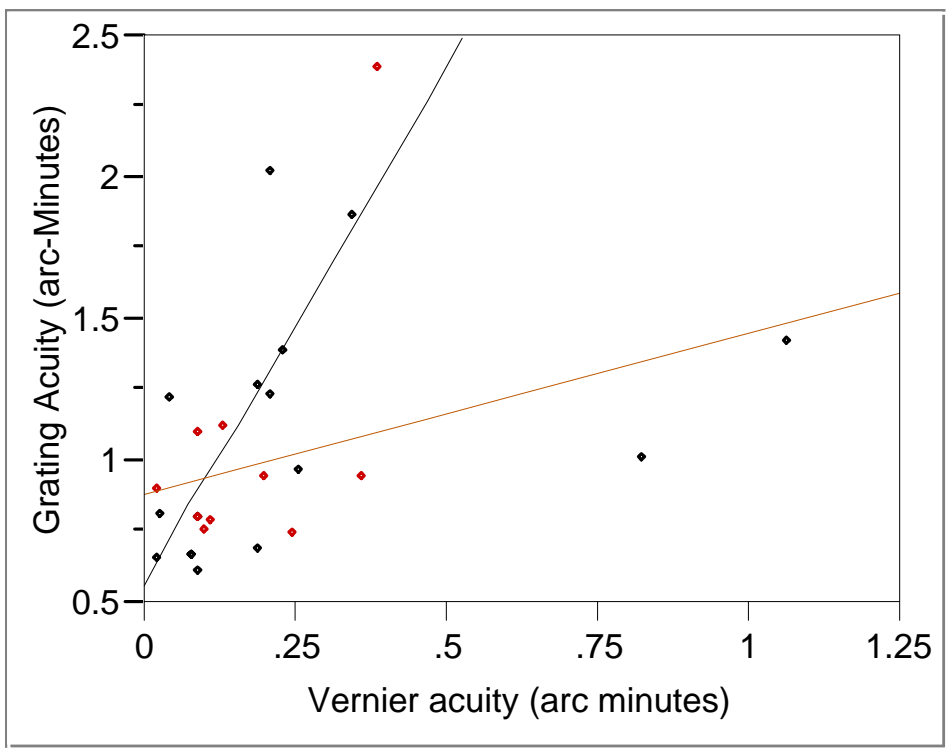

Figure 20: Bivariate Fit of Grating Acuity (MAR) by Vernier Acuity (Arc Minutes)

\section{DISCUSSION}

There are several interesting findings both for monocular as well as binocular tests: 1) Deficits in all the tested monocular functions are present in amblyopes 2) the degree of deficit for Vernier acuity correlates with the loss in grating acuity for anisometropes and not with strabismic subjects. 3) Amblyopes demonstrated significant loss in binocularity when compared to normals, 4) the amount of deficit in binocular functions are different in different types of binocular tests used 5) when amblyopes are reclassified based on the residual binocularity the loss in binocularity correlates with loss in Vernier acuity. These findings were able to support the hypothesis we proposed, that the two amblyopic subtypes are significantly different based on binocular functions. Furthermore, the impairment in the losses of binocular functions can predict the loss in monocular functions. I will discuss these findings systematically, firstly the monocular acuities followed by binocular acuities, and finally the interaction in between these two functions. 


\section{Monocular functions}

Amblyopia is well known as a disorder of spatial vision, which is characterized by reduced resolution ability and compromised contrast sensitivity. The rationale behind using the three monocular acuities in our experimental protocol was because they signify different aspects of spatial visual function. The Snellen acuity measures resolution via a letter chart and is done with maximum contrast. However, it is not a very specific test, because of interaction between spatial frequencies and the use of over-learned stimuli. The grating acuity, on the other hand, measures resolution using sinusoidal gratings at multiple spatial frequencies, and high spatial frequencies are selectively impaired in amblyopes. Finally, Vernier acuity does not test the resolution of a fine pattern, rather the detection of the relative position of an object. The maximum Snellen acuity resolution corresponds to 20/16 which is 0.8 minutes of visual angle. Grating acuity is also approximately equal to Snellen acuity. Vernier acuities have been shown to have much higher resolution. The normal Vernier acuity resolution is on the order of 6-10 seconds of visual angle. Hence, measuring these two acuities along with Snellen acuity enables us to better define the spatial loss.

Classically, and to some extent clinically, the severity of amblyopia is described in terms of deficit in Snellen acuity alone (decrease in visual acuities in between the two eyes by a factor of two). However, concerns have been raised that Snellen acuity alone is not sufficient to describe the whole spectrum of abnormalities. Our group of subjects also highlighted these claims. Snellen acuity in anisometropes is significantly different from normals but strabismics in our subject population did not demonstrate differences from normals, partly because our subjects belonged to mild to moderate subtypes and there was a wider spread in the subject population. Nevertheless, when grating and Vernier acuity was calculated, the effect of diagnosis was evident significantly, both for strabismic and anisometropic subtypes. 
Overall, in amblyopes the degree of resolution demonstrated by grating acuity was much finer than Snellen acuity, which is consistent with many previous studies (Hess and Holliday, 1992;Levi and Klein, 1982b;Gstalder and Green, 1972). This may be due to crowding (see introduction) or interference between multiple spatial frequencies. In our normal subjects the grating acuity was almost equal to Snellen acuity ( 0.81 ' versus $0.89^{\prime}$; in the dominant eye), whereas in amblyopes grating acuity was comparatively higher (1.09' versus 3.07' in strabismics, and 1.21' versus 3.04' in anisometropics). Yet, despite these mean differences, grating acuity was significantly correlated with Snellen acuity, which indicates that loss in grating acuity is proportional to the loss in Snellen acuity, with less severe degree of deficits than Snellen's (Figure 11 and 12).

The Vernier acuity measures a different parameter than the above two acuities. The ratio of grating acuity resolution and Vernier acuity is frequently used to describe the difference in between the two functions. Levi and Carkeet (1993) reported that for normal subjects the resolution ratio is around 7.5:1.0 which means Vernier acuity is 7.5 times finer than grating acuity. The higher resolution ratio in our normal subjects (12.3:1) can be attributed to various stimulus related factors which would predict higher ratios in our case. These include the differences in orientation of offsets of the stimulus (horizontal compared to vertical), whether sinusoidal gratings are used or bars are used, and the number and length of bars used etc. (Levi et al, 1985;(Whitaker, 1993).

Levi et. al. also found that the ratio is considerably reduced in strabismics and those having combined diagnosis of strabismics and anisometropes, even approaching a 1:1 ratio. Our subjects also showed similar findings, with strabismics and anisometropic subjects demonstrating very low resolution ratios compared to normal subjects. Nevertheless, in Levi and colleague's study the resolution ratio for anisometropes was 6.9:1.0 which was significantly different from strabismic subjects (1.4:1.0) In our study group we did not find this difference between the two groups (strabismic 6.1:1.0; and anisometropes 5.8:1.0). In particular, we might have expected the resolution ratio in our anisometropic subjects to be higher. This discrepancy is still unclear; one possible factor is that the data from the above mentioned study are based on the study of just two subjects. 
In addition to these acuities we measured another fundamental aspect of vision: the contrast sensitivities of the eyes. The standard contrast sensitivity functions show their maximum values at middle spatial frequencies of 2-4 cpd in normal subjects. The normal subjects showed peak response at $2 \mathrm{cpd}$ as expected, while the strabismics and anisometropes performed best at $1 \mathrm{cpd}$ due to losses at higher spatial frequencies. The effect of diagnosis was evident in anisometropes, but not in strabismics. This means that the impairment in contrast sensitivity is less severe in strabismic group, as reported by the others (e.g. McKee et. al, 2003). In general, we attribute this greater loss in anisometropes to the developmental deprivation of high spatial frequencies due to blur, which is thought to be an etiologic factor that is distinct from the competitive binocular factor that dominates in the strabismic group.

After comparing these different acuities we were able to establish the following conclusions. Firstly, Snellen and Vernier acuities are impaired by the amblyopic process in a similar manner different than the grating acuity. Secondly, the Vernier acuity impairment is more pronounced in strabismic subgroup as compared to the anisometropic group (Figure 13). Similar results were reported in earlier studies (e.g. Levi and Klein, 1982b). This differential impairment in the two amblyopic subtypes can be explained on the basis of various theories. Because the Vernier thresholds are smaller than the diameter of a photoreceptor, they are referred to as "hyperacuity", and it has been suggested that this reflects cortical processing. Extensive models also have been proposed to explain the loss of Vernier acuity, such as the alteration in the density of cortical receptive fields; spatial disarray in the locations of the filters, and alteration in size and sensitivity of cortical receptive fields (Levi and Klein, 1996;Hess and Field, 1994;Hess and Anderson, 1993). These mechanisms essentially indicate that the deficit in Vernier acuity is due to impairment in neural connections beyond the V1 area (Levi, 1994). Functional MRI (fMRI) data also support this idea. Barnes et al (2001) demonstrated that positional uncertainty is not sufficient to decrease fMRI responses in V1. They propose that feedback connections from extrastriate cortex onto V1 may account for the deficit in the striate cortex. Thus, these findings suggest that the neural deficits at different levels may be different of the visual system in the two amblyopic subtypes. 


\section{Binocular functions}

Binocularity is another parameter which has been shown to be impaired in amblyopes, especially in strabismic amblyopes. In addition, like Vernier acuity, the binocular pathways are more pronounced beyond V1 (V2, V4, MT) (Freeman, 1999). Based on the above background we determined the binocular functions in our subjects. Three parameters which we used were randot stereopsis, binocular motion integration, and binocular contrast integration. Both the amblyopic subtypes showed serious impairments in stereoscopic depth perception, as this function is quite sensitive to abnormal binocular experience. For the motion integration test, the two amblyopic categories were significantly different from normal subjects. Strabismics in general performed worse than anisometropes possibly because binocular connections are impaired due to ocular misalignment. In fact, anisometropes performed very well at the lowest spatial frequencies $(0.312 \mathrm{cpd})$. A possible explanation of this observation is that in amblyopic subjects the lower spatial frequencies are less affected as compared to higher spatial frequencies by spatial blur. In addition, the lower spatial frequencies develop faster than the high spatial frequencies (reaching adult level at around 9 weeks of age) (Norcia et al., 1990). Late developing functions would be expected to be more vulnerable to the effects of abnormal experience.

The third binocular parameter under consideration is the binocular contrast integration function. Data analysis of the effect of a stimulus mask in the non-tested eye offered us various intriguing findings in the normal visual system, in addition to the abnormal findings in amblyopes. Hence I will first discuss the normal subjects, followed by the findings in the amblyopic subjects. The contrast integration data suggested that, in normal subjects, a sub-threshold mask in the non-dominant eye "summates" with the dominant eye and consequently the contrast sensitivity is enhanced. On the other hand, when the non-dominant eye is tested with a sub-threshold mask in the dominant eye, inhibition is observed. With a $0.5 \mathrm{log}$ supra-threshold mask, the dominant eye still showed summation effects, but the non-dominant eye continues to demonstrate inhibition. 
At a 1.0 supra-threshold both the eyes showed inhibition in response to the mask.

These data suggest that in normal subjects the dominant eye tends to summate the stimulus presented in the non-dominant eye if the contrast is in a range above or below the non-dominant eye's threshold. On the other hand, the non-dominant eye seems to have a more restricted range of contrasts that can be shown to the dominant before inhibition occurs. A theoretical physiological model could explain these effects if it is assumed that the dominant eye has slightly more effective connectivity to binocular neurons in visual cortex, e.g., 60:40. The presence of summation versus inhibition would be determined by the respective contrasts of the stimuli in each eye, weighted by this effective connectivity.

In order to explain the contrast integration results for amblyopic subjects, binocularity can discussed in terms of two factors. The first factor is a decrease in total number of binocular neurons (quantitative change). Secondly, for the residual binocular neurons, the effective input of the amblyopic eye may be decreased (e.g., 80:20) (qualitative change). If we consider the performance of the amblyopic eye of the anisometropic subjects in the sub-threshold mask condition, the highly abnormal degree of inhibition may be due to a extreme dominance in the effective input of the fellow eye (e.g., 80:20). This qualitative effect is magnified multiple times because the total number of binocular neurons is not specifically decreased. However, for the amblyopic eye of the strabismic subjects in the sub-threshold mask condition, there is less inhibition than for anisometropic subjects. We speculate that the impact of the 80:20 ratio is mitigated by the absolute reduction in number of binocular neurons. These data suggest that in strabismics, binocular neurons are decreased both qualitatively as well as quantitatively. For the highest contrast masking conditions, the difference between strabismic and anisometropic groups is reduced, but still present, perhaps because the quantitative effect becomes less critical for suprathrehold perception. 
Overall, the three binocular tests in our study suggest that even in the same subject the degree of losses of different binocular functions vary. Stereoscopic tests usually demonstrated the maximum loss followed by motion integration and contrast integration. This further poses a question to the animal studies that report loss in binocular neurons simply on the basis of one binocular function (Sengpiel et al., 1994).

After determining the binocular functions in our subjects we reclassified our subjects based on the residual binocularity based on binocular stereo and motion integration. We named the new subgroups as binocular and non-binocular. We also made a distinction between binocular subjects and normal subjects to test if this group is different from normal subjects or not. The Vernier acuity for this binocular group was normal. However, Snellen and grating acuities demonstrated a significant effect of diagnosis. This strengthened our assumption that Vernier acuity may be processed by common pathways as binocular functions. Furthermore, there was a significant correlation between Vernier and Snellen acuities in the weak eyes of the binocular group while it was absent for the non-binocular groups. Similar results were present when grating acuity was compared with Vernier acuity. These findings indicate that the deficits in Vernier acuities are much more severe in non-binocular group as compared to binocular group, which can not be predicted on the basis of deficit in Grating or Snellen acuites. Overall the re-classification of our subjects based on residual binocularity supports the idea that deficits in Vernier acuities can be predicted by deficits in binocularity.

A possibility that the Vernier acuity pathways may involve a similar level of pathways as binocular pathways is attractive. In fact, binocular interference effects have been demonstrated by showing that presentation of masks in non testing eyes elevated the threshold for detection of Vernier offsets. The authors proposed on this basis that the neural mechanisms mediating Vernier acuity receive binocular inputs (Mussap and Levi, 1995). McKee et al (2003) have proposed that, in the central visual field, the information from the amblyopic eye is continuously suppressed, even with highly visible targets. Complex acuities such as Vernier and Snellen involve competitive mechanisms which 
enhance some neural responses and suppress others. Such selective attention may be partially determined in the early stages in life. In amblyopes, these attentional mechanisms may become biased to the fellow eye. Consequently, in adults, these attentional mechanisms are unavailable to the weak eye even when the preferred is covered, and monocular functions are measured.

The correlation between Vernier acuity and binocularity can further be explained developmentally. The Vernier acuity reaches the adult level only near age 10 years (Shimojo et al., 1984), while it reaches half its maximum resolution at the age of 4 years. Data suggest that binocular acuity development also coincides with the same timeline where the binocular function reaches adult levels at around 9 years (Tychsen, 1992). Grating acuity, in contrast, develops rapidly in the first year of life and then continues to develop more slowly, reaching adult levels near age 3-6 (Gwiazda et al., 1989).

Using all the above conclusions, clinically this study offers a few predictions. Firstly, in adult amblyopes, to better quantify the residual visual functions, the role of Vernier acuity and determination of binocularity may be clinically significant, in addition to traditional classification based on diagnosis. Secondly, for young children who are diagnosed as having strabismus and planned operative correction, the post operative binocularity can be predicted based on Vernier acuity. A number of studies have shown that even after operation many children are unable to achieve the normal binocular vision (Fawcett and Birch, 2003). Finally, the duration of patch treatment for amblyopic eye should be tailored such that the binocular functions are least compromised during patching (McKee et. al, 2003).

In conclusion, a number of binocular and monocular functions on a particular group of subjects were simultaneously measured. Many of the earlier studies have tested only a few of these functions at a time. Most of the binocular and monocular functions we have measured were very well established by previous authors. However, measuring both monocular and binocular functions in the same group of subjects gave us the flexibility to efficiently relate those data and examine any interactions. 


\section{REFERENCES}

1. Asper L, Crewther D, Crewther SG (2000) Strabismic amblyopia. Part 1. Psychophysics. Clin Exp Optom 83: 49-58.

2. Barnes GR, Hess RF, Dumoulin SO, Achtman RL, Pike GB (2001) The cortical deficit in humans with strabismic amblyopia. J Physiol 533: 281-297.

3. Carney T, Shadlen MN (1993) Dichoptic activation of the early motion system. Vision Res 33: 1977-1995.

4. Chung ST, Levi DM (1997) Moving vernier in amblyopic and peripheral vision: greater tolerance to motion blur. Vision Res 37: 2527-2533.

5. Crawford ML, Marc RE (1976) Light transmission of cat and monkey eyelids. Vision Res 16: 323-324.

6. Crewther DP, Crewther SG (1990) Neural site of strabismic amblyopia in cats: spatial frequency deficit in primary cortical neurons. Exp Brain Res 79: 615-622.

7. Daw NW (1998) Critical periods and amblyopia. Arch Ophthalmol 116: 502-505.

8. Delint PJ, Weissenbruch C, Berendschot TT, Norren DV (1998) Photoreceptor function in unilateral amblyopia. Vision Res 38: 613-617.

9. Fawcett SL, Birch EE (2003) Risk factors for abnormal binocular vision after successful alignment of accommodative esotropia. J AAPOS 7: 256-262.

10. Freeman RD (1999) Stereoscopic vision: Which parts of the brain are involved? Curr Biol 9: R610-R613.

11. Gstalder RJ, Green DG (1972) Laser interferometry in corneal opacification. Preoperative visual potential estimation. Arch Ophthalmol 87: 269-274.

12. Gwiazda J, Bauer J, Held R (1989) From visual acuity to hyperacuity: a 10-year update. Can J Psychol 43: 109-120.

13. Harwerth RS, Levi DM (1977) Increment threshold spectral sensitivity in anisometropic amblyopia. Vision Res 17: 585-590. 
14. Hendrickson AE, Movshon JA, Eggers HM, Gizzi MS, Boothe RG, Kiorpes L (1987) Effects of early unilateral blur on the macaque's visual system. II. Anatomical observations. J Neurosci 7: 1327-1339.

15. Hess RF (2001) Amblyopia: site unseen. Clin Exp Optom 84: 321-336.

16. Hess RF, Anderson SJ (1993) Motion sensitivity and spatial undersampling in amblyopia. Vision Res 33: 881-896.

17. Hess RF, Field DJ (1994) Is the spatial deficit in strabismic amblyopia due to loss of cells or an uncalibrated disarray of cells? Vision Res 34: 3397-3406.

18. Hess RF, Holliday IE (1992) The spatial localization deficit in amblyopia. Vision Res 32: 1319-1339.

19. Hubel DH, Wiesel TN (1964) EFFECTS OF MONOCULAR DEPRIVATION IN KITTENS. Naunyn Schmiedebergs Arch Pharmacol 248: 492-497.

20. Kiorpes L, Kiper DC, O'Keefe LP, Cavanaugh JR, Movshon JA (1998) Neuronal correlates of amblyopia in the visual cortex of macaque monkeys with experimental strabismus and anisometropia. J Neurosci 18: 6411-6424.

21. Kiorpes L, McKee SP (1999) Neural mechanisms underlying amblyopia. Curr Opin Neurobiol 9: 480-486.

22. Kumagami T, Zhang B, Smith EL, III, Chino YM (2000) Effect of onset age of strabismus on the binocular responses of neurons in the monkey visual cortex. Invest Ophthalmol Vis Sci 41: 948-954.

23. Legge GE (1979) Spatial frequency masking in human vision: binocular interactions. J Opt Soc Am 69: 838-847.

24. Lerner Y, Pianka P, Azmon B, Leiba H, Stolovitch C, Loewenstein A, Harel M, Hendler T, Malach R (2003) Area-specific amblyopic effects in human occipitotemporal object representations. Neuron 40: 1023-1029.

25. Levi DM (1994) Pathophysiology of binocular vision and amblyopia. Curr Opin Ophthalmol 5: 3-10.

26. Levi DM, Harwerth RS, Manny RE (1979) Suprathreshold spatial frequency detection and binocular interaction in strabismic and anisometropic amblyopia. Invest Ophthalmol Vis Sci 18: 714-725.

27. Levi DM, Klein S (1982a) Differences in vernier discrimination for grating between strabismic and anisometropic amblyopes. Invest Ophthalmol Vis Sci 23: 398-407.

28. Levi DM, Klein S (1982b) Hyperacuity and amblyopia. Nature 298: 268-270. 
29. Levi DM, Klein S (1982c) Hyperacuity and amblyopia. Nature 298: 268-270.

30. Levi DM, Klein SA (1996) Limitations on position coding imposed by undersampling and univariance. Vision Res 36: 2111-2120.

31. McKee SP, Levi DM, Movshon JA (2003) The pattern of visual deficits in amblyopia. J Vis 3: 380-405.

32. Movshon JA, Eggers HM, Gizzi MS, Hendrickson AE, Kiorpes L, Boothe RG (1987) Effects of early unilateral blur on the macaque's visual system. III. Physiological observations. J Neurosci 7: 1340-1351.

33. Mussap AJ, Levi DM (1995) Binocular processes in vernier acuity. J Opt Soc Am A $12: 225-233$.

34. Noorden GK (1977) Mechanisms of amblyopia. Adv Ophthalmol 34: 93-115.

35. Norcia AM, Tyler CW, Hamer RD (1990) Development of contrast sensitivity in the human infant. Vision Res 30: 1475-1486.

36. Pardhan S, Gilchrist J (1992) Binocular contrast summation and inhibition in amblyopia. The influence of the interocular difference on binocular contrast sensitivity. Doc Ophthalmol 82: 239-248.

37. Pardhan S, Whitaker A (2000) Binocular summation in the fovea and peripheral field of anisometropic amblyopes. Curr Eye Res 20: 35-44.

38. Sengpiel F, Blakemore C, Kind PC, Harrad R (1994) Interocular suppression in the visual cortex of strabismic cats. J Neurosci 14: 6855-6871.

39. Shadlen M, Carney T (1986b) Mechanisms of human motion perception revealed by a new cyclopean illusion. Science 232: 95-97.

40. Shadlen M, Carney T (1986a) Mechanisms of human motion perception revealed by a new cyclopean illusion. Science 232: 95-97.

41. Shimojo S, Birch EE, Gwiazda J, Held R (1984) Development of vernier acuity in infants. Vision Res 24: 721-728.

42. Sjostrand J (1981) Contrast sensitivity in children with strabismic and anisometropic amblyopia. A study of the effect of treatment. Acta Ophthalmol (Copenh) 59: 25-34.

43. Westheimer G (1979) The spatial sense of the eye. Proctor lecture. Invest Ophthalmol Vis Sci 18: 893-912.

44. Whitaker D (1993) What part of a vernier stimulus determines performance? Vision Res 33: 27-32. 


\section{CURRICULUM VITAE \\ Ritwick Agrawal, MD}

\section{EDUCATION}

2002-present West Virginia University, Morgantown WV

Department of Neurobiology and Anatomy

Program of study: Integrated Neuroscience Program, Masters in Science

1996-2002 Lucknow University; King George Medical College Lucknow, India

Bachelor in Medicine and Bachelor in Surgery (M.B.B.S.) (equivalent to M.D. in USA)

\section{RESEARCH EXPERIENCE}

2002-present Graduate Student Researcher, West Virginia University.

Principal Investigator: Dr. Janine D. Mendola

Psychophysical studies of human subjects with anisometropic and strabismic amblyopia

2000, summer Summer Research Assistant, Department of Pathology, University of Lucknow

Conducted experiments involving antibodies studies for CNS disease Neurocysticercosis

\section{TEACHING EXPERIENCE}

\section{Courses Taught}

Gross Anatomy (Teaching Assistant, West Virginia University, Fall 2002 and 2003)

\section{Invited and Guest Lectures}

“Transition from Pre-Medical to Medical education," Summer Courses (WVU, 2003)

"Role of glutamate Receptors in Pathophysiology of Asthma" Seminar presentation (Neurobiology and Anatomy, 2003)

\section{HONORS AND AWARDS}

- Dr. N. N. Gupta memorial silver medal and certificate of honor for securing highest marks in Internal Medicine.

- McTagart book prize for being the best qualified in clinical medicine.

- Honors in ten out of thirteen subjects in Medical School.

\section{UNIVERSITY AND VOLUNTEER SERVICE}

- Indian Red Cross Society, Life associate member (2002-present)

- Indian Tuberculosis control and awareness program (2001)

- Student body representative, Physiological Society of Lucknow(19961998)

- Co-coordinator, National meeting of Indian Physiological Society(1997) 


\section{ABSTRACTS AND PRESENTATIONS}

Agrawal, R., Odom, J.V. Schwartz, T. L. Mendola, J. D. (2003) Binocular integration deficits in Anisometropic and Strabismic amblyopia patients. Poster abstract presented at the Van Liere Convocation in West Virginia University. 